\title{
Influence of the Mechanical Environment on the Regeneration of Osteochondral Defects
}

\section{OPEN ACCESS}

Edited by:

Hon Fai Chan,

The Chinese University of

Hong Kong, China

Reviewed by:

Marcus Mumme,

University Children's Hospital

Basel, Switzerland

Lia Rimondini,

University of Eastern Piedmont, Italy

*Correspondence:

Sarah Davis

sarah.davis@port.ac.uk

Tosca Roncada

tosca.roncada@port.ac.uk

Specialty section: This article was submitted to Biomaterials,

a section of the journal Frontiers in Bioengineering and

Biotechnology

Received: 06 September 2020 Accepted: 04 January 2021 Published: 27 January 2021

Citation:

Davis S, Roldo M, Blunn G, Tozzi G and Roncada T (2021) Influence of the Mechanical Environment on the Regeneration of Osteochondral

Defects.

Front. Bioeng. Biotechnol. 9:603408. doi: 10.3389/fbioe.2021.603408

\author{
Sarah Davis ${ }^{1 *}$, Marta Roldo ${ }^{1}$, Gordon Blunn ${ }^{1}$, Gianluca Tozzi ${ }^{2}$ and Tosca Roncada ${ }^{1 *}$ \\ ${ }^{1}$ School of Pharmacy and Biomedical Sciences, University of Portsmouth, Portsmouth, United Kingdom, ${ }^{2}$ Zeiss Global \\ Centre, School of Mechanical and Design Engineering, University of Portsmouth, Portsmouth, United Kingdom
}

Articular cartilage is a highly specialised connective tissue of diarthrodial joints which provides a smooth, lubricated surface for joint articulation and plays a crucial role in the transmission of loads. In vivo cartilage is subjected to mechanical stimuli that are essential for cartilage development and the maintenance of a chondrocytic phenotype. Cartilage damage caused by traumatic injuries, ageing, or degradative diseases leads to impaired loading resistance and progressive degeneration of both the articular cartilage and the underlying subchondral bone. Since the tissue has limited self-repairing capacity due its avascular nature, restoration of its mechanical properties is still a major challenge. Tissue engineering techniques have the potential to heal osteochondral defects using a combination of stem cells, growth factors, and biomaterials that could produce a biomechanically functional tissue, representative of native hyaline cartilage. However, current clinical approaches fail to repair full-thickness defects that include the underlying subchondral bone. Moreover, when tested in vivo, current tissue-engineered grafts show limited capacity to regenerate the damaged tissue due to poor integration with host cartilage and the failure to retain structural integrity after insertion, resulting in reduced mechanical function. The aim of this review is to examine the optimal characteristics of osteochondral scaffolds. Additionally, an overview on the latest biomaterials potentially able to replicate the natural mechanical environment of articular cartilage and their role in maintaining mechanical cues to drive chondrogenesis will be detailed, as well as the overall mechanical performance of grafts engineered using different technologies.

Keywords: osteochondral defects, tissue engineering, biomaterials, articular cartilage, mechanobiology, stem cells, mechanical testing

\section{OSTEOCHONDRAL DEFECTS}

Osteochondral defects are areas of damage that involve both the articular cartilage and the underlying subchondral bone and can be caused by ageing, diseases (such as osteoarthritis and osteochondritis dissecans) or trauma. Osteoarthritis (OA) is a degenerative joint disease that affects over 250 million people worldwide (Hunter et al., 2014). Prevalence of the disease is increasing due to an ageing population and, in the US alone, 70 million people over the age of 65 are at risk of developing OA by the year 2030 (Bhatia et al., 2013). OA, originally thought to be a disease primarily affecting articular cartilage, is now considered to affect all tissues in the diarthrodial joint, including subchondral bone, ligaments, menisci, joint capsule, and synovial 
membrane (Torres et al., 2006; Hunter et al., 2009; Lo et al., 2009; Krasnokutsky et al., 2011). As well as changes to the chondrocytes and the cartilage matrix, osteoarthritis is characterised by structural changes such as joint space narrowing, osteophyte formation and subchondral sclerosis that cause pain and joint immobilisation. Subtle changes to subchondral bone can be observed early, though the precise chronology of how these changes affect the OA process remains to be uncovered and the role of the subchondral bone in initiating and advancing disease progression is now receiving greater attention ( $\mathrm{Li}$ et al., 2013). The crosstalk between subchondral bone and articular cartilage is complex and can induce biomechanical and biochemical changes in the overlying cartilage ( $\mathrm{Hu}$ et al., 2020). The more obvious effect of changes to subchondral bone can be seen in conditions such as osteonecrosis, osteosclerosis, and Osteochondritis Dissecans (OCD). In osteonecrosis, and osteosclerosis imbalances in the bone remodelling process causes changes in bone turnover, mineralization, and subchondral bone volume, reducing overall bone density. This alters the biomechanical environment of the osteochondral unit and causes strain changes in the overlying cartilage during loading that may lead to pathological changes. OCD is a pathologic condition that affects subchondral bone formation resulting in subchondral bone fragments that disrupt the overlying articular surface. The exact causes of OCD are still unknown, yet repetitive microtrauma, abnormal endochondral ossification, and genetic factors are thought to play a role in its development (Grimm et al., 2014). Primarily, repetitive overloading or trauma is thought to disrupt the blood supply resulting in osteonecrosis. This in turn, may induce microcracks in the subchondral bone plate and underlying bone, resulting in fragmentation of bone and cartilage, causing inflammation, and joint pain. Another example is where cartilage loss adjacent to subchondral bone marrow lesions is common and is probably associated with changes in the modulation of this crosstalk (Hunter et al., 2009).

Articular cartilage is a viscoelastic tissue that provides a smooth and lubricated surface for joint movement, which also plays a key role in the absorption and dissipation of loads to the underlying subchondral bone. Healthy articular cartilage is an avascular, a-neural and a-lymphatic tissue, composed mainly of a proteoglycan rich extracellular matrix (ECM), type II collagen and chondrocytes. Mechanical properties of articular cartilage largely depend on ECM composition and organisation, however, mechanical stimulation is essential for cartilage development as well as maintaining cartilage homeostasis (Sanchez-Adams et al., 2014; Prein et al., 2016). Nevertheless, it has been demonstrated that excessive loading, either as single acute event or repetitive stresses, induces the expression of degradative enzymes such as metallopeptidase with a thrombospondin type 1 motif 5 (ADAMTS5) and matrix metalloproteinase-13 (MMP13), affecting matrix composition and hence playing a pivotal role in pathogenesis (Nakagawa et al., 2012; Buckwalter et al., 2013; Houard et al., 2013; Chang et al., 2019). Both OA (particularly post-traumatic osteoarthritis: PTOA) and OCD are associated with high-impact sports and abnormal loading/ joint injury, and therefore tend to affect highly stressed joints such as the knee and elbow. Since mechanical loading plays such a vital role in the initiation and progression of osteochondral defects and associated conditions, a deeper understanding of cartilagebone mechanics is essential for developing better diagnosis and treatment methods.

This review will focus on the biomaterials able to replicate the natural mechanical environment of articular cartilage and the effect of mechanical cues resulting from the use of these scaffolds in directing and enhancing chondrogenesis. Importantly, osteochondral implants must be able to withstand the mechanical environment in the joint, which is responsible for these mechanical cues and that they are tested during their initial development with this environment in mind.

\section{THE MECHANICAL ENVIRONMENT OF NATURAL CARTILAGE}

Articular cartilage can be subdivided into four distinct zones: the superficial zone, the middle zone, the deep zone and the calcified zone (Figure 1A). Each zone exhibits a particular arrangement and organisation of chondrocytes and ECM proteins, mainly collagen type II (Col II) and proteoglycans, determining the tensile strength, flexibility and load-bearing ability of cartilage (Baumann et al., 2019). Since articular cartilage is a non-uniform structure, it presents challenges when trying to determine strain patterns and relative stiffness. This is due to variation in the orientation of collagen fibres, proteoglycan distribution, and molecular/ion content throughout the depth of native cartilage, which is a function of the anatomical location within the joint, and the type of loading applied.

The superficial zone represents the $10-20 \%$ of articular cartilage and contains flattened chondrocytes. In the superficial zone, thin collagen fibres (mainly collagen type II and IX) are tightly packed and aligned parallel to the articular surface to protect deeper layers from shear stress (Sophia Fox et al., 2009; Correa and Lietman, 2017). Moreover, the parallel arrangement of collagen provides tensile stiffness and strength providing the tissue with high mechanical stability. This thin layer acts as a barrier regulating not only the diffusion transport of nutrients and oxygen to the underlying cartilage structures but also the ingress and egress of large biomolecules (Leddy et al., 2008). Lubricin, which is responsible for reducing surface friction, is produced by chondrocytes only in this zone (Correa and Lietman, 2017). The middle zone represents $40-60 \%$ of the articular cartilage and is characterised by sparsely distributed rounded chondrocytes and a proteoglycan rich ECM (consisting mainly of aggrecan) (Fisher et al., 2019). Within the middle zone, collagen type II has thicker fibres and is obliquely distributed. The deep zone is characterised by the highest proteoglycan content and the lowest water concentration. Collagen fibres are thick and run perpendicular to the articular surface (Baumann et al., 2019). Chondrocytes are parallel to the collagen fibres and arranged in columns. Due to the high content of negatively charged proteoglycans, the deep zone is responsible for providing the greatest compressive resistance to articular cartilage (Gilbert and Blain, 2018). The deep zone is reported to have the highest stiffness, along with the superficial zone, corresponding to 


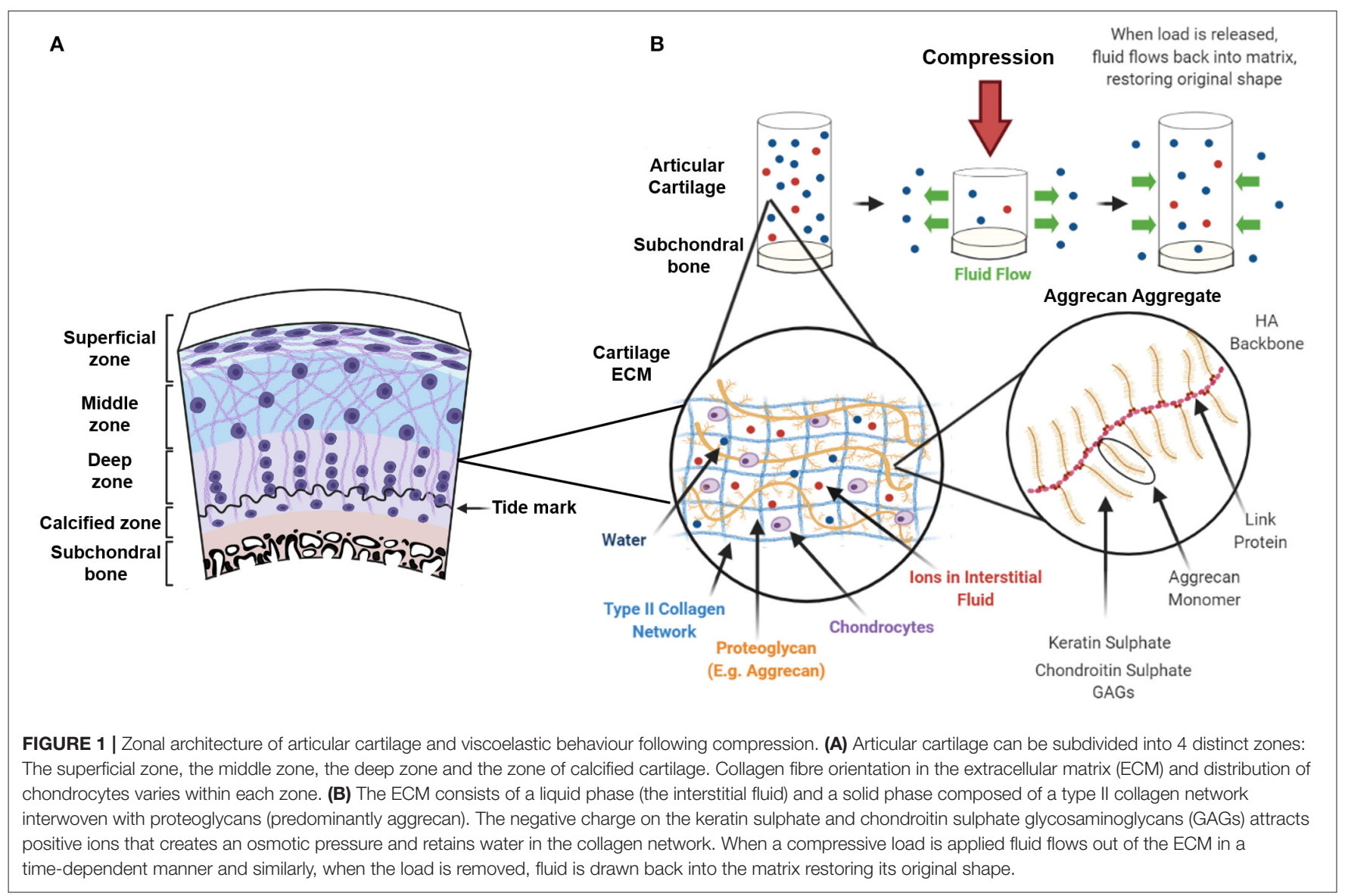

locations where the collagen fibre density is greatest, whereas the middle zone is characteristically softer (Schinagl et al., 1997; Bellucci and Seedhom, 2001). Articular cartilage stiffness has been reported to range from 0.1 to $6.2 \mathrm{MPa}$, with variabilities among studies that depend on sample type and testing setting (Boschetti et al., 2004; Robinson et al., 2016; Patel et al., 2019; Zheng et al., 2019; Guimarães et al., 2020). Within the middle and the deep zone, each chondrocyte is surrounded by a 2$4 \mu \mathrm{m}$ thick collagen type VI rich pericellular matrix (PCM), which forms the chondron. The PCM seems to play a functional role in initiating signal transduction within the cartilage during load-bearing (Leddy et al., 2008). A study by McLeod et al. (2013) showed depth-dependent mechanical inhomogeneity of the elastic moduli of the ECM throughout the cartilage zones, yet zonal uniformity of the PCM elastic moduli in comparison. Cartilage stiffness has also shown to decrease with increasing severity of OA (Kleemann et al., 2005). The calcified zone is characterised by hypertrophic chondrocytes and has a high content of collagen type X ( Col X). It anchors the collagen fibrils from the deep zone to the subchondral bone providing optimal integration and as it is infrequently penetrated by blood vessels it prevents vascularization of the articular cartilage. The zone of calcified cartilage also acts as a transitional zone and is important for reducing stress concentrations at the cartilagebone interface (Boushell et al., 2017). The subchondral bone plate starts at the tidemark separating calcified and non-calcified cartilage. It is a supportive structure that consists of calcified cartilage and underlying subchondral bone that allows the buildup of hydrostatic pressure (Hwang et al., 2008). Damage to the integrity of the subchondral bone affects the generation of hydrostatic pressures and the repair of osteochondral defects often fails to recognise the importance of the subchondral bone plate. In its natural environment, cartilage is subject to a variety of different types of mechanical forces, including tension, compression, shear stress, and torsion. Physiological load on articular cartilage ranges from 5 to $8 \mathrm{MPa}$ during walking and can reach up to $18 \mathrm{MPa}$ when undergoing other activities such as rising from a chair (Clements et al., 2001). Due to the impermeable nature of the calcified cartilage and the low hydraulic permeability of the subchondral bone plate, the resistance to fluid flow within the cartilage results in the build-up of hydrostatic pressures (Hwang et al., 2008). Articular cartilage is resistant to these loads due, in part, to its viscoelastic behaviour resulting from the inter-relationship between the proteoglycan aggregates of the ECM (often referred to as the solid phase), and the interstitial fluid or liquid phase. The negatively charged carboxyl and sulphate groups of the proteoglycans attracts positive ions and creates an osmotic pressure, restrained by the tensile properties of the type II collagen network, which provides the cartilage with its compressive stiffness (Ateshian 
et al., 2004). When a constant force is applied, the interstitial fluid pressure increases, forcing fluid out of the porous ECM in a timedependent manner, creating frictional drag until equilibrium is reached. This frictional drag is inversely proportional to its permeability (Mak, 1986) and gives the cartilage its viscoelastic creep and stress-relaxation characteristics during compression (Mow et al., 1980; Halonen et al., 2014). When strain is kept constant, stress on the tissue increases until it reaches a peak which, due to redistribution of fluid within the cartilage, relaxes over time until equilibrium is reached. Similarly, when the load is removed, fluid flows back into the matrix allowing the cartilage to return to its original state, hence giving the tissue its mechanical properties and ability to withstand compressive loads (Figure 1B). Structural and biochemical variations relating to degenerative changes following injury or pathological conditions such as OA, alters the fluid flow dynamics throughout the tissue and can further affect load-bearing and compressive capability.

Cartilage was originally described as a biphasic material by Mow et al. (1980), composed of the liquid and solid phases as previously described. However, the model was adapted into a triphasic material by Lai et al. (1991) to include the mechanoelectrochemical behaviour of monovalent ions and later the model accounted for the polyvalent ions in the interstitial fluid as forces acting as part of a separate liquid or ion phase ( $\mathrm{Gu}$ et al., 1998). Although the triphasic model is a more recent theory that encompasses a structurally more accurate description of the composition of articular cartilage, the biphasic model highlights the importance of osmotic and hydrostatic pressure within the cartilage and how the tissue resists both compressive and tensile forces (Ateshian et al., 2004). It should be noted that any successful osteochondral implant has to accommodate these forces.

\section{The Effect of Physiological Loading, Overuse, and Disuse on Articular Cartilage}

The high and complex range of physiological loads applied to cartilage are critical for maintaining healthy joint function. Mechanical loading, in the form of moderate exercise, is one of the most important factors for maintaining a homeostatic environment and balancing the anabolic and catabolic response of chondrocytes for ECM synthesis and degradation. Numerous studies have shown reduction in pro-inflammatory cytokines (IL1B, IL-6 TNF- $\alpha$ ), inflammatory mediators (COX-2, $\mathrm{PGE}_{2}$ and NO) (Chowdhury et al., 2001; Fu et al., 2019) and reduction in matrix-degrading enzymes (MMPs and ADAMTSs) in response to dynamic compression (Sun et al., 2012). In vitro studies also confirm anti-inflammatory effects of loading, with an increase in both gene expression, synthesis of type II collagen, aggrecan production (Buschmann et al., 1999; Waldman et al., 2006; Iseki et al., 2019) and stimulation of chondrocyte growth, differentiation, and proliferation. It is also important to note that chondrocytes from different regions of cartilage constitutively express mRNA for cartilage structural proteins in different baseline levels and respond differently to mechanical loading, suggesting that isolating chondrocytes from a non-load-bearing area might significantly affect the quality of the synthesised ECM (Bevill et al., 2009; Briant et al., 2015).

Although there is a genetic predisposition to the development of OA, loading plays a contributory role. Physiological loading is important for maintaining joint homeostasis (Figure 2), whilst abnormal loading caused by obesity, immobilisation, joint instability, overuse, or trauma can cause cartilage degradation and are the main risk factors linked to the development of OA (Arden and Nevitt, 2006). Overloading of the joint, either as a single impact load or cyclic loading causes increased catabolism, chondrocyte necrosis and apoptosis and damage to the collagen network in a dose-dependent manner (Chen et al., 2001; Clements et al., 2004; Hosseini et al., 2014). Most studies report a critical threshold with chondrocyte apoptosis, GAG loss and increased production of inflammatory cytokines above this threshold load (Clements et al., 2001; D'Lima et al., 2001). Kerin et al. (1998) indicated that loads above $10 \mathrm{MPa}$ can result in apoptosis. In comparison, using bovine explants, Loening et al. (2000) showed that chondrocyte apoptosis can occur at 4.5 $\mathrm{MPa}$ as an earlier response to injury which is later followed by degradation of the collagen network at 7-12 MPa (Loening et al., 2000). On the other hand reduced mobility, which is associated with low loading conditions results in upregulation of MMPS, softening and a reduction in proteoglycan content and cartilage thinning (Jurvelin et al., 1986; Vanwanseele et al., 2002; Leong et al., 2011). Impaired joint loading significantly affects articular cartilage ECM composition and as consequence cartilage becomes thinner with reduced ability to absorb loads and shocks resulting in excessive load transmission to the underlying subchondral bone. Abnormal mechanical load can induce bone marrow oedema and subchondral sclerosis (Beckwée et al., 2015; Eriksen, 2015; Donell, 2019).

Articular cartilage is not only sensitive to the type of force applied and the magnitude of load but also to the duration, direction, and frequency of loading (Komeili et al., 2019). Párraga Quiroga et al. (2017) showed that higher strain rates cause more damage to the collagen network, while lower strain rates cause more damage to the non-fibrillar matrix components and that overall cartilage damage is both load and rate dependent. A study by Sadeghi et al. (2015) showed increases in crack length and surface damage with increasing loading frequency above a normal level of $1 \mathrm{~Hz}$. There may also be variation in the material properties of the articular cartilage, in that weight-bearing areas may be more functionally prepared for loading compared to nonweight-bearing areas, and that non-weight-bearing areas may be more susceptible to damage and fibrillation when subject to the same tribological stresses (Moore and Burris, 2015). These factors highlight variability and therefore difficulty for a standard osteochondral graft material to be able to replicate native cartilage in different regions and locations within the same joint, let alone variability between different joints and that under different loading conditions.

\section{Variations in Strain and Stiffness}

In native osteochondral tissue under normal loading conditions, cartilage can experience strains of $2-9 \%$ and can reach up to $20-30 \%$ during vigorous activity, whereas the underlying 


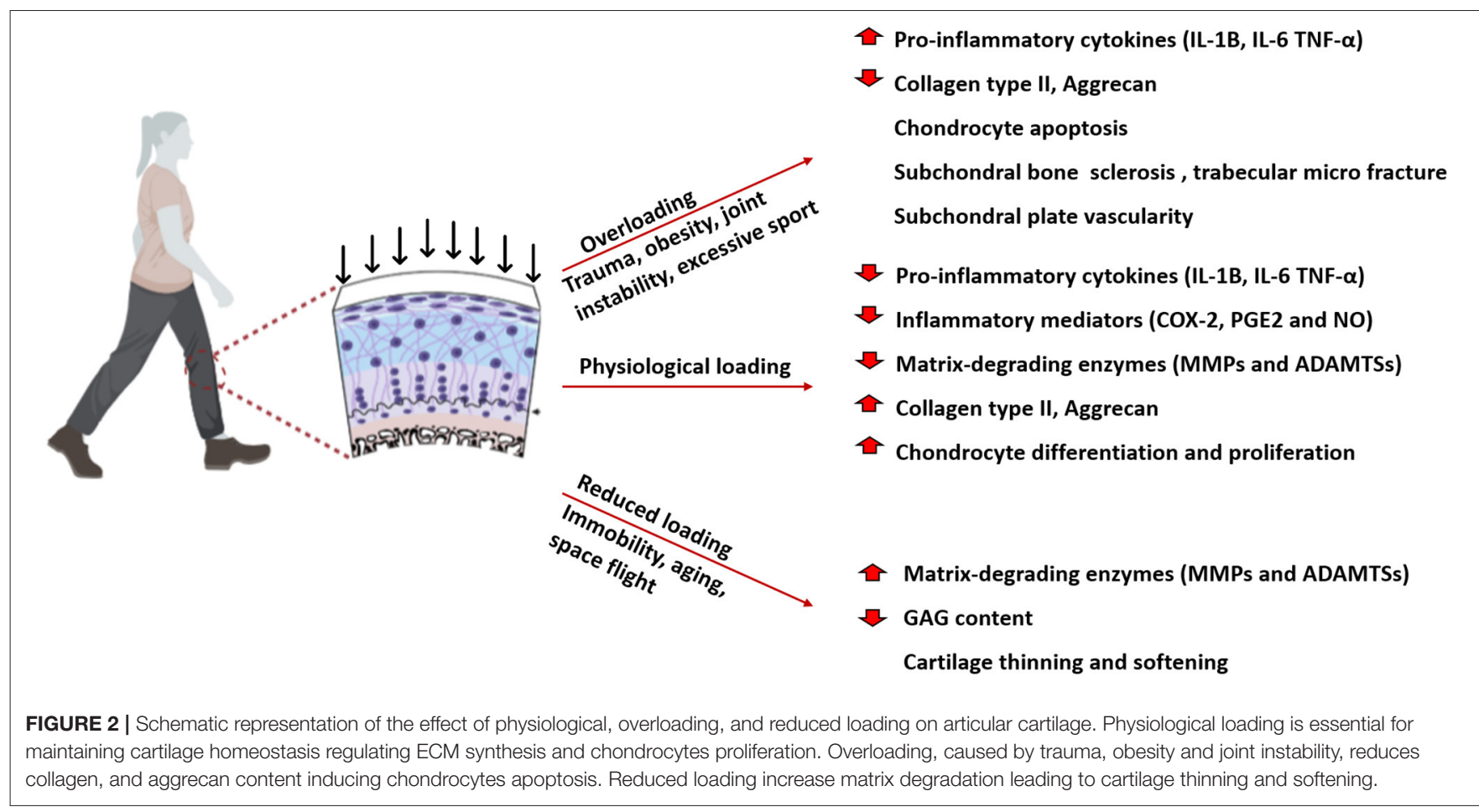

bone experiences strains of $<1 \%$ (Sanchez-Adams et al., 2014; Steinmetz et al., 2015). In addition, calcified cartilage is $\sim 100$ times stiffer than hyaline cartilage and 10 times less stiff than underlying subchondral bone and this transitional zone plays a crucial role in the transmission of loads between these regions (Mente and Lewis, 1994; Madi et al., 2020).

Strain distribution patterns vary depending on the type of loading, with more uniform strains during dynamic loading than static loading conditions and tension-compression non-linearity also causes variations in tensile stiffness (Huang et al., 2005; Komeili et al., 2019). Since cartilage is anisotropic material, the tensile moduli varies depending on the direction of testing and shows increased stiffness parallel to the local split-line patterns which also varies throughout the cartilage depth (Kempson et al., 1973). Variations have also been reported between anatomical locations within the joint, and differences in tensile modulus have been observed between high and low weight-bearing regions. For example, Wong and Sah (2010) showed regional variations in tibial and femoral cartilage, with more axial strain present in tibial cartilage during joint articulation. Several studies have also reported that in tibial and femoral knee condyle, higher strains are present on the medial side compared to the lateral compartment which provides an explanation for differences in mechanical stiffness and is related to contact biomechanics at these sites (Liu et al., 2010; Cotofana et al., 2011; Coleman et al., 2013; Halonen et al., 2014).

Asymmetric strain patterns of natural cartilage create numerous challenges for tissue engineers when analysing strain distribution throughout the cartilage and for replicating this mechanical environment in vitro in order to enhance the maturation of the tissue engineered construct. However, mechanical stimulation has successfully proven to enhance the properties of tissue engineered osteochondral grafts which will be discussed in more detail in this review. It is important to note that in vivo the complex interplay of other supportive tissues such as the menisci, tendons and ligaments (Halonen et al., 2014) which may also be compromised by trauma and $\mathrm{OA}$.

\section{CURRENT CLINICAL THERAPIES}

Due to its avascular nature, the lack of abundant nutrients and low cell density, cartilage has limited regenerative capacity (Lo Monaco et al., 2018; Medvedeva et al., 2018). The treatment modality for repairing osteochondral injuries is dependent on the depth and area of the defect. Several clinical treatments are available to treat osteochondral defects such as microfracture (marrow stimulation), and the use of osteochondral autografts and allografts (Nukavarapu and Dorcemus, 2013; Freitag et al., 2017; Mathis et al., 2018). Microfracture is a surgical technique used to treat chondral defects, it involves perforating the subchondral bone with tiny holes allowing bone marrow mesenchymal stem cells and biomolecules to infiltrate the defect (Erggelet and Vavken, 2016). However, this often promotes the formation of mechanically inferior fibrocartilage with little evidence of type II collagen deposition (Redondo et al., 2018). For the treatment of larger osteochondral defects, where subchondral bone damage is seen tissue grafts of both cartilage and bone may be used. Osteochondral autograft transfer and mosaicplasty, have been used to treat full-thickness defects up to $4 \mathrm{~cm}^{2}$. 
During this procedure, chondral defects are replaced with plugs of the patient's own healthy articular cartilage and bone that are harvested from non-weight-bearing areas and transferred to predrilled holes at the defect site (Rowland et al., 2019). The outcome depends on age, sex and size of the lesion. In the case of large lesions, up to $8-9 \mathrm{~cm}^{2}$, multiple plugs can be used but with a risk of significant donor site morbidity (Richter et al., 2016; Kato et al., 2018). Unlike autograft, allografts use full-thickness cartilage that can be harvested from locations that correlate with the defects to be filled allowing more precise matching of the size and contour of the articular surface (Assenmacher et al., 2016; Haber et al., 2019). Even though allografts can be performed as a single staged procedure and have shown good survival rate in short to medium term (5-10 years), long term follow-up has shown considerable reoperation (30.2\%) and high failure rates (18.2\%) over time (Familiari et al., 2018). Moreover, allografts are limited by the lack of tissue supply, low cell viability due to graft storage and possible immunorejection (Yang et al., 2017; Mathis et al., 2018).

Among the current clinical therapies, multi-layered cell-free scaffolds have been considered and are currently under preclinical and clinical evaluation. TruFit CB (Smith and Nephew) is a synthetic plug designed to be used with microfracture in order to improve the mechanical stability of the defect. Initial studies showed positive results with the regeneration of cartilage in a goat model, however, clinical studies revealed that $70 \%$ of patients required reoperation and the plug failed specifically in restoring the subchondral bone (Williams and Gamradt, 2008; Joshi et al., 2012). The bone-layer of TruFit $\mathrm{CB}$ is made of PGA and calcium phosphate, two materials that degrade quickly post-implantation and mechanical failure has resulted in the plug being withdrawn from the market (Fraser et al., 2016; Tseng et al., 2020). D’Ambrosi et al. (2019), investigated the clinical and radiological efficacy of MaioRegen, a try-layered collagen-based scaffold, in restoring osteochondral knee defects. Despite the promising satisfactory and reliable results at mid-term follow-up, this systematic review revealed that, in terms of clinical improvement at follow-up, MaioRegen is not superior to conservative treatment or other cartilage techniques. Therefore, there is still an unmet need for an optimal biomaterial system that favours simultaneous bone and cartilage regeneration. Although current clinical approaches can reduce pain and improve the quality of a patient's life, none of them has routinely achieved complete healing of the osteochondral lesion. Non-biological man-made materials can be used to partially replace the joint (e.g., unicompartmental knee replacement) or when the whole joint is severely affected it is likely that a total joint replacement (TJR) will be required as an end-stage intervention. In the elderly $\mathrm{TJR}$ is a successful end stage treatment for OA however, younger patients have a significantly higher risk of undergoing revision due to implant limited lifespan (25 years), periprosthetic joint infection or aseptic mechanical failure (Meehan et al., 2014; Stambough et al., 2014; Bayliss et al., 2017; Evans et al., 2019). To overcome these limitations, in the last two decades, research has focused on tissue engineering (TE) as a possible solution for osteochondral regeneration and repair of cartilage.

\section{TISSUE ENGINEERING APPROACHES}

The most common tissue engineering approach involves the use of a biocompatible scaffold, cells (e.g., stem cells) and/or a combination of bioactive molecules such as growth factors and cytokines. Autologous chondrocyte implantation (ACI) is a procedure for the regeneration of cartilage introduced by Brittberg et al. (1994), where autologous chondrocytes are isolated from a non-load-bearing site of the cartilage, expanded in vitro for 4-6 weeks and subsequently injected under a periosteal flap that is sutured onto the cartilage positioned over the defect (Könst et al., 2012). Although this technique has been used for two decades with successful surgical outcomes, the main issue is that two operations are required, one to obtain the cells, using arthroscopy and the other usually an open procedure to implant the cells (Minas et al., 2014; Mistry et al., 2017; Zikria et al., 2019). Matrix-induced autologous chondrocytes implantation (MACI) was originally developed to improve the biological performance of autologous chondrocytes cells and simplify surgical procedures (Andriolo et al., 2020). As with ACI, chondrocytes are isolated from a non-loadbearing area and cultured in vitro, however, this approach aims to deliver autologous chondrocytes in a biopolymer membrane. MACI ${ }^{\circledR}$ is also the name of a commercially available membrane of porcine collagen type I/III (Genzyme, United States). Several types of membranes and scaffolds have been developed for MACI procedures such as Novocart ${ }^{\circledR} 3 D$ (TETEC Tissue Engineering Technologies AG, Germany) a collagen-chondroitin-sulphate based membrane, CaRes ${ }^{\circledR}$ Cartilage Regeneration System (Arthro-Kinetics, Germany) a collagen type I matrix and Cartipatch ${ }^{\circledR}$ (Tissue Bank of France, France) a monolayer agarose-alginate hydrogel (Vilela et al., 2018). However, MACI failed to prevent fibrocartilaginous healing and the integration of the scaffold into host hyaline cartilage is still unsatisfactory due to the intrinsic features of fully differentiated chondrocytes with their poor capability of tissue remodelling. Moreover, MACI still requires a two-step surgery, cartilage biopsy and cell cultivation, thus increasing the total cost (Behrens et al., 2006; Zikria et al., 2019). To further improve ACI outcomes and obtain a more reliable tissue repair, third generation of ACI has been developed, in which autologous chondrocytes are cultured in $3 \mathrm{D}$ to form spherical aggregates with a self-synthesised extracellular matrix. Spheroids of human autologous matrix-associated chondrocytes (Spherox) is an advanced tissue medicinal product with European Medicines Agency (EMA) market approval for the treatment of osteochondral defects up to $10 \mathrm{~cm}^{2}$ (Niemeyer et al., 2020). However, due to differences in cartilage phenotype isolating chondrocytes from a non-load-bearing area might significantly affect the quality of the synthesised ECM (Bevill et al., 2009; Briant et al., 2015).

So far there appears to be little difference in outcomes of these cell therapies and tissue engineering approaches when compared with osteochondral autograft transfer system, mosaicplasty or microfracture surgery. Further, when harvested in vitro, chondrocytes undergo dedifferentiation exhibiting a flattened, fibroblast-like morphology. In these conditions they 
produce a higher amount of collagen type I and collagen type $\mathrm{X}$ inducing the formation of fibrocartilage. An advantage of growing spheroids of chondrocytes isolated from biopsies is that the cartilage phenotype is better maintained than when cells are grown on flat tissue culture plastic. However, all of these approaches fail to fully repair the lesion in severe osteochondral defects, where both subchondral bone and articular cartilage are damaged (Davies and Kuiper, 2019). A significant proportion of research is focusing on the use of stem cells for cartilage repair since a large number of cells can be obtained from different sources such as bone marrow, peripheral blood, adipose tissue, dental pulp, placenta, and the umbilical cord (Tozzi et al., 2016). However, selectively promoting stem cell differentiation into appropriate cell lineages in situ is still challenging. An expanding field of research has demonstrated that mechanical cues from the environment could drive tissue formation and maturation, suggesting that combining scaffolds with mechanical properties that can drive stem cell differentiation could provide a solution for osteochondral defects where both bone and cartilage formation is required.

\section{OSTEOCHONDRAL GRAFTS MATERIALS THAT CAN BE USED TO REPLICATE THE NATURAL MECHANICAL ENVIRONMENT}

The development of an osteochondral implant that replicates the structure of articular cartilage and subchondral bone remains challenging for tissue engineers. Material selection plays a pivotal role in the development of osteochondral grafts as it potentially contributes to the mechanical properties of the scaffold (Jahr, 2017; Bonani et al., 2018).

\section{Natural Materials}

Natural materials such as collagen, chitosan, hyaluronic acid, silk, and alginate have been extensively used in TE for their biocompatibility, degradability and bioactivity (Jeuken et al., 2016; Li et al., 2018b). Natural materials are often used in the form of hydrogels with a highly hydrated viscoelastic matrix, tunable swelling behaviour and mechanical properties depending on the type and degree of crosslinking (Catoira et al., 2019; Mantha et al., 2019). Moreover, natural materials provide multiple binding sites for cell-ECM interaction. Multiple scaffolds for osteochondral TE in the clinical market are mainly composed of collagen type I (NOVOCART ${ }^{\circledR} 3 \mathrm{D}, \mathrm{MACI}^{\circledR}, \mathrm{CaReS}^{\circledR}$, NeoCart ${ }^{\circledR}$, Maioregen ${ }^{\circledR}$ ) (Kon et al., 2009; Crawford et al., 2012; Petri et al., 2013; Saris et al., 2014; Zak et al., 2014). Collagen can be extracted from various tissues and sources, for example, studies have reported that purified collagen can be isolated from vertebrate (generally rat, bovine, porcine and sheep) skin, tendon, cartilage and bone as well as from marine invertebrates (jellyfish, sponges, octopus, squid, cuttlefish, starfish) (Barzideh et al., 2014; Langasco et al., 2017). Even though collagen type I does not represent the main component of articular cartilage, several studies have demonstrated its pro-chondrogenic effects (Calabrese et al., 2017a,b; Xia et al., 2018). Preference of type I collagen in TE is largely attributed to its availability, its general biocompatibility and safety approvals granted by various agencies; however, high production costs and poor mechanical properties of pure collagen scaffolds are still major limitations (Table 1) (Dong and Lv, 2016; Ghodbane and Dunn, 2016). In comparison, Gelatin is derived by thermal denaturation of collagen and can be manufactured at a much lower cost and in larger quantities (Grover et al., 2012). Gelatin shows low antigenicity, it possesses integrin-binding sites, and it is completely resorbable in vivo. However, at body temperature gelatin hydrogels are not stable, limiting their possible use as a biomaterial. Van Den Bulcke et al. (2000) first described gelatin methacrylate (GelMA), a chemically modified form of gelatin that can be stabilised through photo-crosslinking allowing the formation of a hydrogel that is stable at body temperature. The modulus of GelMA-based biomaterial can be controlled by varying the degree of substitution and macromer concentration (Sadeghi et al., 2017), for example, Gan et al. (2019) has modified GelMA hydrogels by intercalating oligomers of dopamine methacrylate obtaining flexible hydrogels with compressive modulus of $2.5 \mathrm{MPa}$ and shape-recovery ability. GelMA has also been used in combination with hyaluronic acid (HA), which forms the backbone of aggrecan and therefore plays a critical role in maintaining the viscoelastic and mechanical properties of cartilage (Hemmati-Sadeghi et al., 2018). HA acts also as a biochemical cue enhancing chondrogenic differentiation of MSCs, promoting chondrocyte proliferation and preventing chondrocyte de-differentiation by activating CD 44 (Chen et al., 2018; Li et al., 2018a; Yamagata et al., 2018). The use of HA in TE affects matrix deposition by cells, thus enhancing the dynamic and equilibrium moduli during in vitro culture (Levett et al., 2014). Recently silk fibroin (SF) has also been investigated in the context of osteochondral TE due to its biocompatibility, low immunogenicity, slow degradation rate, and remarkable mechanical properties (Qi et al., 2017). Silk has a high tensile strength (around 300-740 MPa) and depending on the source and production method, it is possible to obtain elastic moduli ranging from $1 \mathrm{MPa}$ to $17 \mathrm{GPa}$, making it a favourable biomaterial not only for cartilage repair but also for subchondral bone (Koh et al., 2015; Peng et al., 2019). Li J. J. et al. (2015), developed a bi-layered scaffolds for osteochondral regeneration using silk fibroin for the cartilage layer and a silkcoated strontium-hardystonite-gahnite ceramic scaffold for the bone layer. The silk layer exhibited highly elastic behaviour showing 91\% strain at failure, indicating that the silk scaffold could stretch to approximately twice its original length before breakage, which is desirable for the cartilage phase. When tested under compression the biphasic scaffold approximated the biomechanical behaviour of osteochondral tissue, as it could maintain structural integrity under large compressive stresses while retaining the ability for shape recovery when hydrated, in addition the stiff bone phase could withstand large compressive stresses with minimal deformation.

Among natural polysaccharides, both alginate and chitosan have potential for cartilage repair (Xu et al., 2008; Yao et al., 2016; Ewa-Choy et al., 2017; Henrionnet et al., 2017; Merlin Rajesh Lal et al., 2017; Ruvinov et al., 2018; Huang et al., 2019). Alginate is a biodegradable and biocompatible material, derived 
TABLE 1 | Summary of advantages, disadvantages, and mechanical properties of naturally-derived materials.

\begin{tabular}{|c|c|c|c|c|}
\hline $\begin{array}{l}\text { Natural } \\
\text { materials }\end{array}$ & Advantages & Disadvantages & Mechanical properties & References \\
\hline Collagen type I & $\begin{array}{l}\text { Low immunogenicity } \\
\text { Degraded in vivo by MMPs }\end{array}$ & $\begin{array}{l}\text { High production cost } \\
\text { Low mechanical properties }\end{array}$ & $\begin{array}{l}\text { Permeability } 0.044-0.072 \\
\mathrm{~mm} 4 / \mathrm{Ns} \\
\text { Compressive modulus } \\
3.5-3.7 \mathrm{kPa}\end{array}$ & Ghodbane and Dunn, 2016 \\
\hline Gelatin & $\begin{array}{l}\text { Manufactured at a lower cost and in large } \\
\text { quantities } \\
\text { Low antigenicity } \\
\text { Resorbable }\end{array}$ & $\begin{array}{l}\text { Not stable at body } \\
\text { temperature }\end{array}$ & $\begin{array}{l}\text { Compressive modulus } \\
0.75-6 \mathrm{kPa}\end{array}$ & Chen S. et al., 2016 \\
\hline GelMA & $\begin{array}{l}\text { Stabilised form of gelatin } \\
\text { Photocrosslinkable } \\
\text { Varying the degree of substitution is } \\
\text { possible to vary mechanical properties }\end{array}$ & $\begin{array}{l}\text { UV crosslinking may have a } \\
\text { negative effects on } \\
\text { encapsulated cells }\end{array}$ & $\begin{array}{l}\text { Compressive modulus 2-30 } \\
\mathrm{kPa}\end{array}$ & $\begin{array}{l}\text { Sadeghi et al., } 2017 \\
\text { Klotz et al., } 2016\end{array}$ \\
\hline $\begin{array}{l}\text { Hyaluronic acid } \\
(\mathrm{HA})\end{array}$ & $\begin{array}{l}\text { Enache MSCs chondrogenic differentiation } \\
\text { Maintaining viscoelastic and mechanical } \\
\text { properties in native cartilage } \\
\text { Can be physically and chemically modified }\end{array}$ & $\begin{array}{l}\text { Rapid degradation and poor } \\
\text { mechanical properties }\end{array}$ & $\begin{array}{l}\text { Elastic modulus of modified } \\
\mathrm{HA} 1-70 \mathrm{kPa}\end{array}$ & $\begin{array}{l}\text { Chen C. H. et al., 2016; Li } \\
\text { et al., 2018a; Yamagata et al., } \\
2018 \\
\text { Lee et al., } 2018 \\
\text { Trombino et al., } 2019\end{array}$ \\
\hline Silk fibroin & $\begin{array}{l}\text { Biocompatibility } \\
\text { Low immunogenicity } \\
\text { Slow degradation rate } \\
\text { Remarkable mechanical properties }\end{array}$ & $\begin{array}{l}\text { Brittleness and swelling } \\
\text { behaviour limits its } \\
\text { applications in tissue } \\
\text { engineering }\end{array}$ & $\begin{array}{l}\text { High tensile strength } 300-700 \\
\text { MPa and elastic modulus } \\
\text { ranging from } 1 \mathrm{MPa} \text { to } 17 \mathrm{GPa}\end{array}$ & $\begin{array}{l}\text { Koh et al., 2015; } \\
\text { Chen et al., 2018; Peng et al., } \\
2019\end{array}$ \\
\hline Alginate & $\begin{array}{l}\text { Biodegradable Biocompatible } \\
\text { Re-differentiate chondrocytes after } \\
\text { monolayer culture Support chondrogenic } \\
\text { phenotype } \\
\text { Tunable mechanical properties }\end{array}$ & Lack of adhesion ligands & $\begin{array}{l}\text { Elastic modulus } \\
0.15-0.55 \mathrm{MPa}\end{array}$ & Kaklamani et al., 2014 \\
\hline Chitosan & $\begin{array}{l}\text { Biocompatibility Biodegradability } \\
\text { Antibacterial properties }\end{array}$ & $\begin{array}{l}\text { Display poor mechanical } \\
\text { properties }\end{array}$ & $0.13-0.199 \mathrm{MPa}$ & Thomas et al., 2017 \\
\hline
\end{tabular}

from seaweed that is composed of $\alpha$ - $D$-mannuronic acid and $\beta$-l-glucuronic acid. Studies have shown that it can support chondrogenic phenotype promoting a rounded morphology of isolated chondrocytes and the synthesis of type II collagen and proteoglycans (Homicz et al., 2003; Caron et al., 2012; Angelozzi et al., 2017; Aurich et al., 2018). Chondrogenic differentiation of stem cells isolated from bone marrow, adipose tissues, Wharton's Jelly, and dental pulp has been promoted by growing cells within alginate gels (Huang et al., 2015; Reppel et al., 2015; Ewa-Choy et al., 2017; Mata et al., 2017; Baba et al., 2018). Although much lower than the compressive modulus of native cartilage the mechanical properties of alginate scaffolds can be modified to give values of 0.15-0.55 $\mathrm{MPa}$ using divalent ions $\left(\mathrm{Mg}^{2+}, \mathrm{Ca}^{2+}\right.$, and $\mathrm{Sr}^{2+}$ ) (Kaklamani et al., 2014). However, the main limitation of alginate-based materials is the lack of adhesion ligands that are essential for cell-attachment and to overcome this, bioactive components such as collagen may be incorporated (Bian et al., 2011; Lee and Mooney, 2012; Ganesh et al., 2013).

Another natural polymer employed is chitosan, derived from partial deacetylation of chitin, used in TE for its biocompatibility, in vivo degradation and antibacterial properties (Cheung et al., 2015; Varun et al., 2017; Huang et al., 2019). Chitosan hydrogels have been shown to support the proliferation of chondrocytes and MSCs in vitro and to improve the deposition of cartilaginous ECM both in vitro and in vivo (Griffon et al., 2006; Elder et al.,
2013; Faikrua et al., 2013; Sheehy et al., 2015; Huang et al., 2019; Scalzone et al., 2019). However, since chitosan display poor mechanical properties, crosslinking or combination with other materials is required to optimise the elastic modulus for osteochondral TE (Muzzarelli et al., 2015; De Mori et al., 2019; Kusmono and Abdurrahim, 2019; Scalzone et al., 2019). Thomas et al. (2017) tuned the stiffness of chitosan-hydrogels by blending increasing concentrations of hyaluronic acid dialdehyde and the degree of crosslinking to obtain hydrogels with a Young's modulus of $0.13 \mathrm{MPa}$ and $0.199 \mathrm{MPa}$. However, a reinforced chitosan-based scaffold failed to regenerate bone and cartilage in vivo suggesting that the crosslinking treatment may have affected its overall degradation (Roffi et al., 2019). Therefore, a careful balance between the mechanical properties and degradation rate should be considered when designing osteochondral scaffolds using this material.

\section{Synthetic Materials}

Synthetic materials are attractive substitutes for load-bearing tissues, since the mechanical properties can be tailored by altering the molecular weight and/or via the use of different processing methods (Grigore, 2017). Synthetic polymers, including poly(ethylene glycol) (PEG), polylactide (PLA) and its derivatives poly(L-lactide) (PLLA) and poly(lactic-co-glycolic acid) (PLGA), polyglycolic acid (PGA), poly( $\varepsilon$-caprolactone) 
TABLE 2 | Summary of advantages, disadvantages, and mechanical properties of synthetic materials.

\begin{tabular}{|c|c|c|c|c|}
\hline $\begin{array}{l}\text { Synthetic } \\
\text { materials }\end{array}$ & Advantages & Disadvantages & Mechanical properties & References \\
\hline PEG & $\begin{array}{l}\text { High solubility in water Hydrophilicity } \\
\text { Biocompatibility } \\
\text { Inertness } \\
\text { Non-immunogenicity }\end{array}$ & $\begin{array}{l}\text { Lack of specific binding motifs } \\
\text { for cell attachment }\end{array}$ & $\begin{array}{l}\text { Equilibrium modulus } 0.01-2.46 \mathrm{MPa} \\
\text { Hydraulic permeability 10-13-10-16 } \\
\mathrm{m} 2 / \mathrm{Pa} \\
\text { Tensile modulus } 0.02-3.5 \mathrm{MPa}\end{array}$ & $\begin{array}{l}\text { Nguyen et al., } 2012 \\
\text { Zhu, } 2010\end{array}$ \\
\hline PGA & $\begin{array}{l}\text { Biocompatible } \\
\text { Bioresorbable }\end{array}$ & $\begin{array}{l}\text { Loses its mechanical integrity } \\
\text { between } 2-4 \text { weeks in vivo }\end{array}$ & Tensile modulus $7 \mathrm{GPa}$ & $\begin{array}{l}\text { Woodard and Grunlan, 2018; } \\
\text { Gorth and Webster, } 2011\end{array}$ \\
\hline PLA & $\begin{array}{l}\text { PLA is more hydrophobic compared to } \\
\text { PGA, leading to a slower hydrolysis rate. }\end{array}$ & $\begin{array}{l}\text { Lack of specific binding motifs } \\
\text { for cell attachment }\end{array}$ & $\begin{array}{l}\text { Tensile modulus } 3 \mathrm{GPa} \\
\text { Tensile strength 50-70 MPa }\end{array}$ & $\begin{array}{l}\text { Narayanan et al., } 2016 \\
\text { Samavedi et al., } 2013\end{array}$ \\
\hline PLGA & $\begin{array}{l}\text { Modulation of Young's modulus and } \\
\text { degradation rate, Sustained mechanical } \\
\text { integrity after implantation }\end{array}$ & $\begin{array}{l}\text { Lack of specific binding motifs } \\
\text { for cell attachment }\end{array}$ & $\begin{array}{l}\text { Compression storage modulus } \\
3.2-4.6 \mathrm{MPa}\end{array}$ & $\begin{array}{l}\text { Baker et al., } 2009 \\
\text { Gentile et al., } 2014\end{array}$ \\
\hline PVA & $\begin{array}{l}\text { Biodegradable Biocompatible } \\
\text { Adjustable mechanical properties }\end{array}$ & $\begin{array}{l}\text { Lack of specific binding motifs } \\
\text { for cell attachment }\end{array}$ & $\begin{array}{l}\text { Tensile strength } 1-17 \mathrm{MPa} \\
\text { Elastic modulus } 0.0012-0.85 \mathrm{MPa} \\
\text { Low friction coefficients }(\mu) 0.02-0.05\end{array}$ & $\begin{array}{l}\text { Lin et al., } 2017 \\
\text { Teixeira et al., } 2019 \\
\text { Sánchez-Téllez et al., } 2017\end{array}$ \\
\hline PCL & $\begin{array}{l}\text { Adjustable mechanical strength } \\
\text { Possibility to produce hydrogel, porous } \\
\text { scaffold, electrospun nanofibers }\end{array}$ & $\begin{array}{l}\text { Lack of specific binding motifs } \\
\text { for cell attachment }\end{array}$ & $\begin{array}{l}\text { Compressive modulus 6.63-56.46 } \\
\text { MPa } \\
\text { Tensile Modulus 6.03-46.04 MPa }\end{array}$ & Olubamiji et al., 2016 \\
\hline
\end{tabular}

(PCL) and poly(vinyl alcohol) (PVA), are used to form hydrogels, porous scaffolds and nanofibrous scaffolds (Sánchez-Téllez et al., 2017; Yang et al., 2017; Castilho et al., 2018; Dai et al., 2018; Kudva et al., 2018; Critchley et al., 2020). The main disadvantage of these materials is the lack of specific binding motifs for cell attachment, but this can be improved through functionalization or by combining with more bioactive materials. PEG hydrogels have been used in TE due to their high solubility in water, hydrophilicity, biocompatibility, inertness, and nonimmunogenicity (Table 2). They have also shown to maintain cell viability and promote chondrogenic ECM synthesis (Bryant and Anseth, 2002). By varying the molecular weight and the concentration of PEG precursors, Nguyen et al. (2012) obtained hydrogels with equilibrium modulus (0.01-2.46 MPa), hydraulic permeability [ranging from $10^{-13}$ to $10^{-16}\left(\mathrm{~m}^{2} / \mathrm{Pa} \mathrm{s}\right)$ ] and tensile modulus (0.02-3.5 MPa) similar to articular cartilage. Steinmetz et al. (2015) also developed a multi-layer PEG hydrogel resembling the zonal organisation of the osteochondral tissue. Although the compressive modulus did not match that of the native cartilage and bone when subject to mechanical loading, the strain distribution pattern was similar to osteochondral tissue with higher strain in the cartilage-like layer. When $7.5 \%$ apparent strains were applied to the hydrogel the local strains in the cartilage-like layer and in the bone-like layer were 15 and $2 \%$ respectively.

PGA exerts high tensile modulus (7 GPa) but due to its relatively hydrophilic nature and instability in aqueous solution loses its mechanical integrity between two and four weeks in vivo (Gunatillake and Adhikari, 2003; Gorth and Webster, 2011; Woodard and Grunlan, 2018). PLA exists in several isoforms and the presence of one extra methyl group makes it more hydrophobic compared to PGA, leading to a slower hydrolysis rate. PLA possesses a high tensile modulus (3 GPa) and strength (50-70 MPa) (Gorth and Webster, 2011; Samavedi et al., 2013).
PLGA can be synthesised using a different ratio of PGA and PLA that allows modulation of both Young's modulus and the degradation rate which can be, from a few weeks up to months, resulting in sustained mechanical integrity after implantation (Félix Lanao et al., 2013; Samavedi et al., 2013; Gentile et al., 2014). PVA is a biodegradable and biocompatible polymer, from which hydrogels can be prepared at different polymer concentrations to obtain tensile strengths in the cartilage range of 1-17 $\mathrm{MPa}$ as well as an elastic modulus up to $0.85 \mathrm{MPa}$ (Karimi and Navidbakhsh, 2014; Lin et al., 2017; Teixeira et al., 2019). PVA hydrogels exhibit limited swelling when tested at osmotic pressures similar to that of articular cartilage, which is desirable for soft tissue engineering to preserve the initial size and shape and to prevent interfacial debonding (Holloway et al., 2011; Oliveira et al., 2019). A non-biodegradable PVA based hydrogel (Cartiva ${ }^{\circledR}$ ) exerts biphasic behaviour similar to normal articular cartilage under compression and it is currently under clinical trial for first metatarsophalangeal joint hemiarthroplasty (Brandao et al., 2020).

PCL is an FDA approved biodegradable aliphatic linear polyester and it is one of the most investigated polymers for tissue engineering applications due to its adjustable mechanical strength. PCL can be used to produce porous scaffolds as well as electrospun nanofibers (Zhu et al., 2014; Panadero et al., 2016). Visser et al. (2015) incorporated PCL microfibers into GelMA obtaining reinforced hydrogels with mechanical properties similar to articular cartilage. Castilho et al. (2019) also used PCL to successfully develop a bi-layered construct that mimics the zonal structure as well as the functional properties of native cartilage. This construct incorporated a thin superficial tangential layer, mimicking the collagen organisation in the superficial layer of the cartilage, that improved the load-bearing properties of the micro-fibre reinforced hydrogel with a peak modulus of $473 \mathrm{kPa}$ under unconfined compression as well as 


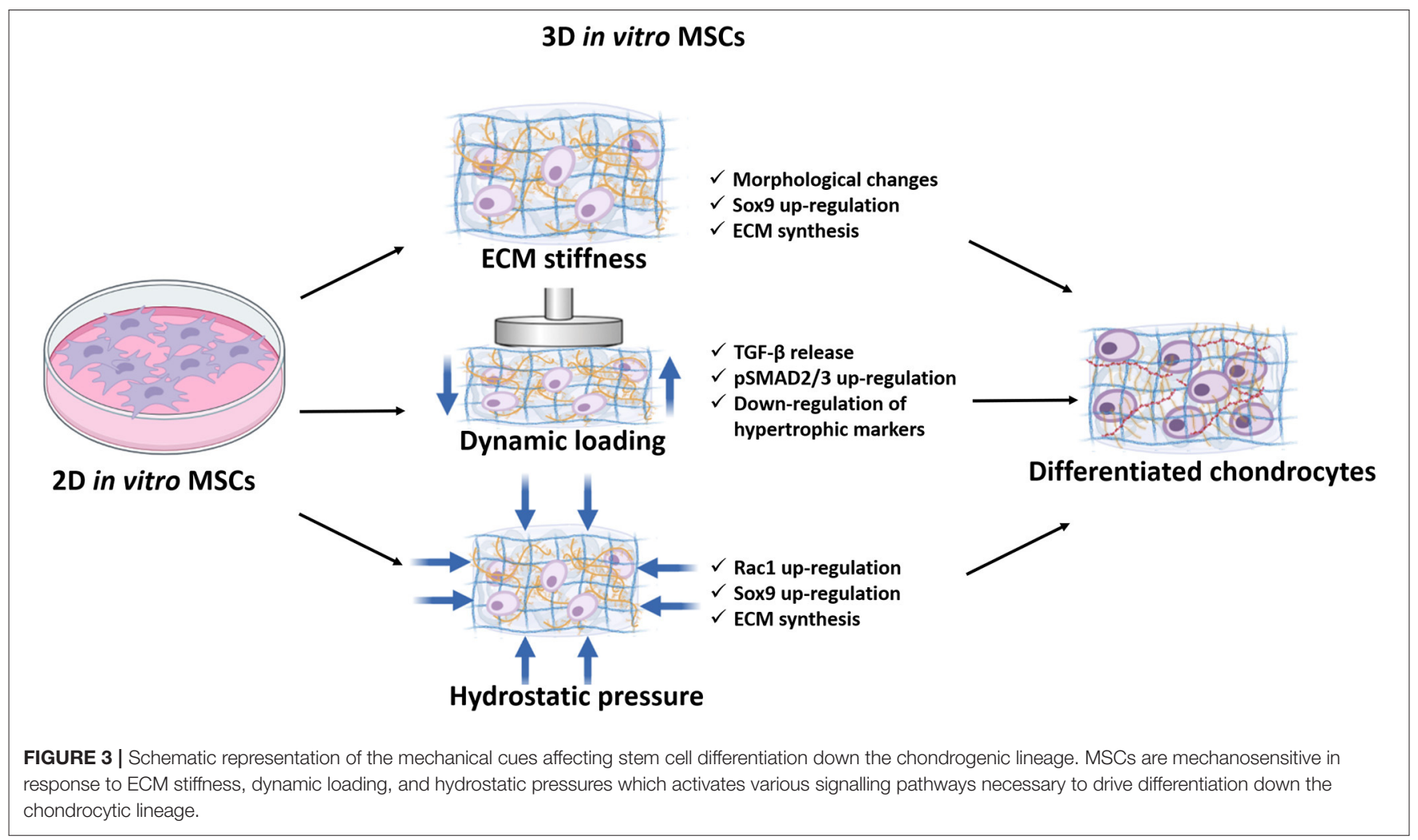

exhibiting relaxation rates similar to those for native cartilage (Castilho et al., 2019). Controlling the mechanical properties of scaffolds for osteochondral TE is essential, not only to maintain structural integrity and withstand high mechanical loading in vivo, but also to provide environmental mechanical cues to selectively guide stem cell differentiation into the appropriate osteochondral phenotypes.

\section{MECHANICAL CUES AFFECTING STEM CELL DIFFERENTIATION}

MSC commitment to the chondrocytic lineage is governed by TGF- $\beta$ and WNT/ $\beta$-catenin signalling (Usami et al., 2016). In particular, the activation of TGF- $\beta /$ SMAD $2 / 3$ pathways is essential for the intracellular phosphorylation of Smad2 and Smad3, which then translocate to the nucleus to activate and stabilise the transcription factor Sex determining region Y (SRY) Box 9 (SOX9), that is the master regulator of chondrogenesis (Furumatsu et al., 2009; Coricor and Serra, 2016; Pfeifer et al., 2019). SOX9, along with SOX5 and SOX6 expression is required during embryonic development as well as in postnatal maintenance of articular cartilage regulating expression of ECM molecules, such as collagen (mainly types II, IX, XI) and proteoglycans (aggrecan, decorin).

To differentiate MSCs into chondrocytes the use of growth factors, such as TGF- $\beta$, is usually required. However, its use in the clinic is limited as it leads to the expression of hypertrophic markers such as Col X, MMP13 and alkaline phosphatase
(ALP), which will eventually lead to cartilage mineralization. There is increasing evidence that environmental (such as low oxygen tension) and mechanical cues control stem cell fate. In particular (as described in Figure 3), MSCs are highly mechanosensitive and respond to both passive stimuli such as stiffness, and dynamic stimulation such as mechanical loading and hydrostatic pressure that signals through integrins and focal adhesion (FA) protein complex, transducing physical signals into biochemical signals.

\section{Regulation of MSCs Differentiation by ECM Stiffness}

In vivo each tissue is characterised by a specific stiffness, which regulates tissue development and homeostasis by affecting cell migration, proliferation, morphology, cell phenotype and ECM protein production (Ehrbar et al., 2011; Handorf et al., 2015; Hwang et al., 2015; Du et al., 2016; Sun et al., 2017; Xia et al., 2017; Abbas et al., 2019; Chu et al., 2019; d'Angelo et al., 2019; Saidova and Vorobjev, 2020). Engler et al. (2006) originally explored the effect of stiffness on MSCs using polyacrylamide hydrogels mimicking the native elasticity of brain, muscle and osteoid. This work demonstrated that stiffness not only affects MSC morphology showing that the expression of the neurogenic marker $ß$ tubulin 3 was enhanced on soft substrates and Runx2 on stiff substrates. Interestingly, this work showed that growth factors tend to be less selective compared to matrix stiffness in driving lineage specification. MSCs pre-conditioned on a matrix with a specific stiffness for 3 weeks cannot be reprogrammed, 
TABLE 3 | Summary of the effect of mechanical cues on MSCs differentiation.

\section{EFFECT OF MECHANICAL CUES ON MSCS}

\begin{tabular}{|c|c|c|c|c|}
\hline $\begin{array}{l}\text { Substrate } \\
\text { stiffness }\end{array}$ & Soft substrates (1-30 kPa) & Intermediate substrate (0.1-5MPa) & Stiff substrates (5-300 MPa) & References \\
\hline & $\begin{array}{l}\text { MSCs on soft substrates exhibit a } \\
\text { rounded chondrocyte-like morphology } \\
\text { Higher expression levels of } \\
\text { chondrogenic markers } \\
\text { Unable to withstand mechanical loads }\end{array}$ & $\begin{array}{l}\text { Mechanically competent } \\
\text { Stiffness in the range of native cartilage } \\
\text { MSCs found to express high level of } \\
\text { SOX9 and Col II on substrates stiffness } \\
\text { of } 0.8 \mathrm{MPa} \text { and } 4.7 \mathrm{MPa}\end{array}$ & $\begin{array}{l}\text { Highly organised cytoskeleton } \\
\text { Spindle-shape morphology }\end{array}$ & $\begin{array}{l}\text { Engler et al., 2006; Park et al., } \\
\text { 2011; Wang et al., 2016; } \\
\text { Olivares-Navarrete et al., } 2017\end{array}$ \\
\hline \multirow[t]{2}{*}{$\begin{array}{l}\text { Dynamic } \\
\text { loading }\end{array}$} & $0.15-1.5 \%$ compressive strain $1 \mathrm{~Hz}$ & $\begin{array}{l}10 \% \text { compressive strain } 1 \mathrm{~Hz} \text { from } \\
\text { day } 0\end{array}$ & $\begin{array}{l}10 \% \text { compressive strain } 1 \mathrm{~Hz} \text { after } 1 \\
\text { week of pre-culture }\end{array}$ & \\
\hline & $\begin{array}{l}\text { Dynamic loading, delayed } \\
\text { osteogenesis. } \\
\text { Mineral deposits was diffuse in the } \\
\text { unloaded condition } \\
\text { while under dynamic loading was } \\
\text { concentrated and spatially restricted to } \\
\text { the central region }\end{array}$ & $\begin{array}{l}\text { Compression from day } 0 \text { has negative } \\
\text { effects on MSC chondrogenesis }\end{array}$ & $\begin{array}{l}\text { Dynamic culture increase synthesis of } \\
\text { GAG aggrecan, Col II and increase } \\
\text { expression SOX9 } \\
\text { Upregulation of } \\
\text { phosphorylated-SMAD2/3 } \\
\text { MSCs under static culture MSCs } \\
\text { exhibited higher of hypertrophic } \\
\text { markers }\end{array}$ & $\begin{array}{l}\text { Thorpe et al., 2010; Zhang et al., } \\
\text { 2015; Sawatjui et al., 2018; Aziz } \\
\text { et al., 2019; Cao et al., } 2019\end{array}$ \\
\hline \multicolumn{2}{|c|}{$\begin{array}{l}\text { HydrostaticLow HP stimulation } \\
\text { pressure } \quad 100-300 \mathrm{kPa}\end{array}$} & $\begin{array}{l}\text { Physiological HP stimulation in the } \\
\text { cartilage layer } \\
1-10 \mathrm{MPa}\end{array}$ & $\begin{array}{l}\text { High HP } \\
25 \mathrm{MPa}\end{array}$ & \\
\hline & $\begin{array}{l}\text { IHP upregulate osteogenic markers } \\
\text { Increase expression of Runx2, ALP and } \\
\text { osteopontin }\end{array}$ & $\begin{array}{l}\text { HP applied continuously it negatively } \\
\text { affects SOX9, Coll II and aggrecan gene } \\
\text { expression } \\
\text { IHP positively affects SOX9 and Col II } \\
\text { expression even without external } \\
\text { growth factors and enhances } \\
\text { cartilaginous matrix deposition }\end{array}$ & $\begin{array}{l}\text { Inhibited aggrecan and Col II } \\
\text { Pro-osteoarthritic effects }\end{array}$ & $\begin{array}{l}\text { Correia et al., 2012; Li et al., } \\
\text { 2016; Montagne et al., 2017; } \\
\text { Stavenschi et al., 2018; } \\
\text { Stavenschi and Hoey, } 2019\end{array}$ \\
\hline
\end{tabular}

suggesting that modulation of ECM modulus could be a powerful tool to drive stem cell differentiation. When cultured on stiff substrates, MSCs develop a highly organised cytoskeleton showing a spindle-shape morphology (Table 3). Conversely, MSCs on soft substrates exhibit a rounded chondrocyte-like morphology and express higher levels of chondrogenic markers. Park et al. (2011) compared collagen type II and GAG synthesis on a soft collagen hydrogel, on plastic coated with a thin layer of collagen and on polyacrylamide hydrogels with different stiffnesses ( 1 and $15 \mathrm{kPa}$ ). They showed an increase in expression of chondrogenic markers both on the soft collagen hydrogel and on the $1 \mathrm{kPa}$ substrate. The effect of substrate stiffness together with biochemical cues was investigated by Wang et al. (2016). They showed that HA enhanced MSC chondrogenesis, evidenced by upregulated of aggrecan and Col II expression and this effect was more distinct when cells were grown in soft hydrogels $(3 \mathrm{kPa})$, while this effect was reversed in the stiff hydrogel $(90 \mathrm{kPa})$. It is important to note that cartilage stiffness varies between 0.1 and $6.2 \mathrm{MPa}$, and soft hydrogels will fail to maintain their structural integrity after implantation (Wang et al., 2016; Zheng et al., 2019; Guimarães et al., 2020). Olivares-Navarrete et al. (2017) compared both cytoskeletal organisation and gene expression of MSCs and auricular chondrocytes grown on methyl acrylate/methyl methacrylate (MA/MMA) polymer surfaces with elastic moduli ranging from 0.8 to $310 \mathrm{MPa}$ mimicking the stiffness of articular cartilage and cortical bone. MSCs appeared to be elongated on the less stiff surfaces with a higher number of adhesion plaques on the 4.7 MPa substrate. After 7 days without exogenous stimuli by cytokines or other factors associated with cartilage differentiation, the expression of SOX9, Col II, aggrecan and cartilage oligomeric matrix protein (COMP) in MSCs showed an increasing trend with decreasing stiffness. This work showed that mimicking the native elasticity of cartilage enhances chondrogenic phenotype without exogenous stimuli. Nevertheless, it is also important to consider that osteochondral tissue exhibits different stiffness among the different layers, and an implant displaying a layering or gradient approach with varying stiffness, might be more effective in reproducing the native architecture of the tissue as well as selectively promoting ECM synthesis.

\section{Role of Dynamic Loading in MSCs}

During ambulation mechanical load plays an important role in maintenance and degeneration of articular cartilage affecting gene expression of Col II, aggrecan, and degenerative enzymes (MMPs). Interestingly dynamic stimulation also affects MSC differentiation and the quality of ECM synthesised. A study from Thorpe et al. (2008) revealed a negative effect of long term dynamic compression on MSCs cultured in agarose hydrogels. This study reported that unconfined compression at $10 \%$ strain and $0.5 \mathrm{~Hz}$ for $1 \mathrm{~h} /$ day significantly reduced GAG production and Col II synthesis compared to static culture. Interestingly, the application of dynamic compression from day 0 inhibits chondrogenesis even in the presence of TGF- $\beta 3$ (Thorpe et al., 2010). In contrast, the inhibition of chondrogenesis in response to dynamic compression was not observed if the MSCs were 
first allowed to undergo chondrogenesis. Consistent with these results, Sawatjui et al. (2018) studied the effect of dynamic compression of both MSCs and chondrocytes derived from osteoarthritic joints seeded on silk fibroin scaffold, pre-cultured for 1 week, and subsequently subjected to compression with $10 \%$ dynamic strain at $1 \mathrm{~Hz}, 1 \mathrm{~h}$ /day for 2 weeks. This study showed that dynamic compression significantly enhanced the synthesis of Col II and aggrecan along with an increase of compressive modulus. Cao et al. (2019) seeded rabbit derived MSCs into collagen scaffolds under $10 \%$ compressive sinusoidal strain at $1 \mathrm{~Hz}$ frequency, for $2 \mathrm{~h}$ /day for 21 days. Starting from the second week of culture, the morphology of MSCs in the dynamic culture group exhibited a rounded chondrocyte-like morphology, whereas cells remained spindle shaped in static culture. Dynamic culture also promoted GAG synthesis as well as aggrecan, Col II and SOX9 expression compared to the static culture. Zhang et al. (2015) demonstrated that delayed dynamic compression positively affected MSC chondrogenesis through phosphorylated-SMAD2/3 enhancing matrix deposition and suppressing hypertrophy. Further MSCs under free swelling condition exhibited higher expression of ERK (involved in chondrocyte hypertrophy) along with upregulation of MMP13, Runx2, and Col X. In addition, Gardner et al. (2017) demonstrated that multiaxial loads on MSC led to endogenous production and secretion of TGF- $\beta 1$ as well as the activation of the secreted latent TGF- $\beta 1$. Taken together these data suggest that dynamic load positively affects MSC chondrogenesis, however, MSCs should first be differentiated before applying loads. Consequently in vitro differentiation of stem cells prior to implantation could be critical for osteochondral tissue engineering.

\section{Hydrostatic Pressure and MSCs Differentiation}

Cartilage ECM is characterised by a high water content and low permeability, and as a consequence when a load is applied the resistance of fluid flow generates hydrostatic pressure (HP). In vivo $\mathrm{HP}$ varies between 2 and $10 \mathrm{MPa}$ with peaks of 18 $\mathrm{MPa}$ during intense activities such as jumping or running (Elder and Athanasiou, 2009; Correia et al., 2012). Several studies have demonstrated that the application of HP on MSCs might have a pro-chondrogenic effect. Angele et al. (2003) examined the effects of cyclic hydrostatic pressure on MSCs aggregates showing a significant increase in GAG and collagen content at days 14 and 28 compared to the unloaded control. Furthermore, Miyanishi et al. (2006a) studied MSCs in pellet culture exposed to intermittent hydrostatic pressure (IHP) and demonstrated an increase in expression of SOX9, Col II, and aggrecan with or without the addition of TGF- $\beta 3$. In a second study the authors also demonstrated that the magnitude of loading modulated chondrogenic gene expression and cartilage matrix protein deposition in MSCs pellets in the presence of TGF- $\beta 3$ suggesting that the magnitude of the load could enhance MSCs chondrogenesis (Miyanishi et al., 2006b). In fact, physiological levels of HP (5MPa) significantly enhance cartilaginous matrix deposition (Correia et al., 2012; Li et al., 2016). Conversely, high HP (25 MPa up to $24 \mathrm{~h}$ ) on the ATDC5 cell line markedly affecting the expression of matrix remodelling related genes, apoptosis-related genes and strongly inhibited aggrecan and Col II, suggesting that excessive loads induce pro-osteoarthritic effects (Montagne et al., 2017). Interestingly the use of low HP, in the range of $100-300 \mathrm{kPa}$, has been demonstrated to direct MSCs differentiation into the osteogenic lineage upregulating the expression of Runx2, ALP and osteopontin (Stavenschi et al., 2018; Stavenschi and Hoey, 2019). Not only the magnitude of load, but also the length of the stimulation affects matrix deposition. In fact, it has been shown that when the load is applied continuously, it negatively affects SOX9, Col II and aggrecan gene expression (Correia et al., 2012; Li et al., 2016).

One of the major limitations of cartilage tissue engineering is the formation of fibrocartilage, which has inferior mechanical properties compared to articular cartilage. HP appears to affect hypertrophic genes, increasing Col I, Col X and MMP13 (Ogawa et al., 2009, 2015; Li et al., 2016). Conversely, other studies revealed decreasing levels of Col I and Col X under IHP (Vinardell et al., 2012; Saha et al., 2017; Rieder et al., 2018). Freeman et al. (2017) demonstrated that HP without any external growth factors resulted in enhanced chondrogenesis along with reduction in hypertrophic markers. Additionally, when MSCs were stimulated with HP alone and subsequently induced to undergo osteogenic differentiation without any external mechanical stimulation, the production of hypertrophic markers was reduced compared to those exposed to chondrogenic growth factors alone. These studies suggested that the application of intermittent hydrostatic pressure could potentially lead to a stable differentiation of MSCs into the chondrogenic lineage without the use of growth factors. However, it is important to note that the intensity and the frequency of HP applied differ among studies, suggesting that standardisation is required to obtain consistent results.

\section{TESTING OSTEOCHONDRAL GRAFT MATERIALS}

The success of osteochondral grafts depends on the restoration of surfaces representative of native articular cartilage to provide smooth joint movement during joint articulation. Implanted grafts also need to be structurally stable to withstand physiological loading conditions of up to 4-5 times body weight during walking (Morrison, 1970; Bellucci and Seedhom, 2001) with peak stresses in the knee ranging from 2 to $10 \mathrm{MPa}$ and at a loading frequency of approximately $1 \mathrm{~Hz}$ (Brand, 2005; Sadeghi et al., 2015). Osteochondral defects cause high contact stresses at the rim, that vary depending on the size of the defect causing uneven strain distribution (Brown et al., 1991; Kock et al., 2008). These abnormal contact stresses and strains at the defect perimeter cause damage and chondrocyte death that could impair integration and healing of the graft, leading to reduced functionality of the joint, or cartilage damage (D'Lima et al., 2001; Wu et al., 2002). However, contact stresses can be restored to pre-operative levels, resembling intact cartilage depending on appropriate fitting, alignment, length and surface 
of the graft (D'Lima et al., 2001; Koh et al., 2004; Kock et al., 2006 , 2008). One of the major issues is that post-implantation osteochondral implants will be subject to continual cyclic loads, encompassing a range of shear and tensile forces which will affect the biological response of the graft and test the integration with the surrounding native cartilage. However, specific test methods to demonstrate the performance of these grafts have not yet been defined.

\section{Standardisation}

Osteochondral grafts are classed by the International Standard Organisation (ISO) as implantable medical devices that as defined in ISO 13485, 2016, are implanted into the human body via surgical intervention and are intended to remain in place after the procedure. ISO 14630:2012 specifies the general requirements for non-active surgical implants, whereas ISO 21536:2007 is the level 3 standard referring more specifically to knee joint replacement implants. These standards include performance, design, materials, evaluation and sterilisation and the tests needed to demonstrate compliance with these regulations. More specific standards relating to tissue engineered cartilage constructs include the quantification of sulfated glycosaminoglycans (sGAG) (ISO 13019: 2018), and the evaluation of tissue morphology including collagen fibre orientation and anisotropy in vivo (ISO/TR 16379:2014) have also been defined. Despite these biological and clinical evaluation there are no specific requirements for mechanical testing, and there is uncertainty as to whether articular cartilage implants are classified as partial joint replacement implants and should therefore be subject to mechanical characterisation (Marchiori et al., 2019).

In contrast, the FDA provides more specific mechanical testing criteria for the use of tissue engineered cartilage constructs, which highlights inconsistencies with regard to global standardisation. The FDA guidance document for products intended to repair or replace knee cartilage includes specifications for in vivo animal studies (that will be discussed later in this review) and various in vitro mechanical tests. It states that "mechanical testing should address the following: the ability of the implant to withstand expected in vivo static and dynamic loading (i.e., compression, shear, and tension); analysis of fixation method (i.e., strength of integration between the product and surrounding native tissue); and propensity to generate wear debris." It is also recommended that static mechanical behaviour such as the maximum recoverable compressive strain, the aggregate modulus (HA), the shear modulus $(G)$, and permeability $(\kappa)$ as well as the dynamic complex shear modulus are included. Degradable scaffolds should also include assessment of failure properties over time and some examples of confined or unconfined compression and indentation are suggested for analysing the mechanical properties of implants.

\section{In vitro Compressive Testing (Confined, Unconfined and Indentation)}

The most frequent in vitro test are usually biological assays to evaluate the biocompatibility (ISO 1099), cytotoxicity (ISO 10993-5), gene expression and matrix deposition (ISO 13019 quantification of sulfated glycosaminoglycans for evaluation of chondrogenesis) (Keong and Halim, 2009; Li W. et al., 2015). However, mechanical evaluation of osteochondral scaffolds are essential to ensure graft stability in the initial period following implantation (Bowland et al., 2015). As reviewed by Patel et al. (2019), compression testing is the most common test performed both on cartilage and tissue engineered construct. Compression test can be performed using unconfined and confined compression and indentation (Figure 4). For unconfined compression testing, the sample is placed between two impermeable steel plates allowing the Young's modulus to be measured directly from the linear portion of the stressstrain curve produced (Korhonen et al., 2002; Griffin et al., 2016). For confined compression the sample is either tested using a porous indenter or placed in a porous chamber with an impermeable indenter to ensure fluid flow. Confined compression allows the measurement of both the aggregate modulus (determined when fluid flow stops) of the specimen as well as the permeability (Boschetti et al., 2004). While unconfined and confined compression require the cartilage sample or the scaffold to be tested within a chamber, indentation allows the test to be performed on a whole osteochondral specimen (Griffin et al., 2016; Tozzi et al., 2020). Compression tests can be performed by applying a strain at a constant rate (ramp), by applying a strain to a target level and holding the strain constant (stress-relaxation) or applying a cyclic strain (dynamic) (Scholten et al., 2011; Vikingsson et al., 2015; Coluccino et al., 2016; Kundanati et al., 2016). Compression tests can be also loadcontrolled, applying a rapid load that is then kept constant, measuring sample strain over time (Oyen, 2014; Patel et al., 2019). Both the FDA and International Cartilage Repair Society (ICRS) recommend both static and dynamic compression tests to assess the mechanical behaviour of the osteochondral graft. However, specific guidelines on how to perform each test have not been agreed, which leads to inconsistent or non-physiologically relevant data. Cartilage and osteochondral grafts should be tested under the same conditions, as the strain rate influences the stressstrain curves, implying that the higher the strain rate the higher the modulus will be. As reviewed by Patel et al. (2019), 48\% of the studies that analysed cartilage repair constructs under ramp mechanical testing, were tested to more than $20 \%$ strain, more than double the compressive strain that articular cartilage was tested to. Considering that the physiological average strain is $10 \%$ the data produced using higher strain might not be reliable (Chan et al., 2016).

In addition to the standard mechanical tests previously mentioned, implants need to be tested after periods in vivo (for dynamic and static loading) and under loading conditions of compression, tension, and shear. Analysis of fixation within the defect is also required (e.g., mechanical push-out tests to assess integration) and assessment of the bioreactivity of any device-generated wear debris.

\section{In vivo Animal Models}

In vivo animal models are crucial preliminary studies to assess the safety and efficacy of newly developed cartilage TE implants. However, currently there are no exact guidelines 


\begin{tabular}{|lll|}
\hline TEST & CONFIGURATION \\
\hline $\begin{array}{l}\text { Confined } \\
\text { compression }\end{array}$ & $\begin{array}{l}\text { The sample is either tested using a } \\
\text { porous indenter or placed in a permeability } \\
\text { porous chamber with an } \\
\text { impermeable indenter to ensure } \\
\text { fluid flow }\end{array}$ \\
\hline $\begin{array}{l}\text { Unconfined } \\
\text { compression }\end{array}$ & $\begin{array}{l}\text { The sample is placed between two } \\
\text { impermeable steel plates allowing } \\
\text { from the linear portion of the stress- } \\
\text { strain curve }\end{array}$ \\
\hline Indentation & $\begin{array}{l}\text { The test can be performed in situ } \\
\text { allowing to test the whole } \\
\text { osteochondral plug }\end{array}$ & $\begin{array}{l}\text { Elastic modulus (Young's } \\
\text { modulus) }\end{array}$ \\
\hline
\end{tabular}

FIGURE 4 | Standard mechanical tests for assessing osteochondral grafts. Confined compression tests using either an impermeable chamber and porous indenter; or porous chamber with an impermeable indenter, are useful for defining the aggregate modulus. Unconfined compression tests and indentation tests can determine the elastic modulus (Young's modulus).

for the comparison of animal models, assessment of defect size/location and description of appropriate mechanical tests for the assessment of implantable devices such as osteochondral grafts to repair and regenerate articular cartilage. The FDA recommends using combined animal studies with appropriate mechanical testing to assess biological response, durability (using large animal models) and toxicology (U. S. Food Drug Administration, 2011). In addition, dose response (of bioactive scaffolds), lesion size and location, appropriate endpoints, and continual arthroscopic/MRI evaluation should also be taken into consideration (U. S. Food Drug Administration, 2011). Nevertheless, despite these recommendations there are no clearly defined protocols, test criteria, or test parameters for mechanical testing. It is also acknowledged that there is no optimal animal model for cartilage repair, which may also lead to variability between studies.

Small animal models (mouse, rat and rabbit) are mainly used for "proof of concept" studies as a translational step between in vitro tests and larger animal/human studies. Rabbit models have spontaneous intrinsic healing capabilities of cartilage defects that must be taken into consideration, therefore, they usually require additional validation in other animal models (Shapiro et al., 1993). Other variables to consider when choosing the most appropriate animal model are thickness of cartilage and joint suitability, skeletal/ cartilage maturity, defect type, size and location of the defect, availability and post-operative care (Hurtig et al., 2011). Canine models, like humans, often suffer from diseases such as OA and OCD which makes them useful for assessing cartilage regeneration in pathologic conditions (Chu et al., 2010). Large animal models (goat, sheep, pig and horse) more closely reflect intended clinical use for assessing toxicity, integrity and inflammatory responses for both small and larger defects in load bearing environments. Since cartilage thickness in equine stifle joints $(1.5-2.0 \mathrm{~mm})$ is the most similar to human cartilage thickness $(2.2-2.5 \mathrm{~mm})$ the horse is the closest approximation for creating both partial and full thickness defects for preclinical cartilage repair studies (Frisbie et al., 2006; McIlwraith et al., 2011). Nevertheless, in most animal models the loading, thickness and geometry of the joint surface is very different to that of humans.

\section{Mechanical Push-Out Tests for Assessing Integration}

Mechanical push-out tests are useful pre-clinical studies to evaluate the maximum forces needed for graft failure and for assessing integrative repair with host cartilage over time (Theodoropoulos et al., 2011). A biopsy punch is normally used to create a cylindrical defect filled with the TE scaffold or osteochondral graft to be tested. After a culture and/or treatment period to allow a certain amount of integration with the host tissue, the inner core is pushed out of the outer ring using a mechanical push-out rod. The calculated amount of force needed for displacement (or failure of the graft) allows an assessment of integrative strength at the interface to be assessed. A recent study 
by Bowland et al. (2020) performed a series of push-in and pushout tests to assess the mechanical stability of bovine and porcine osteochondral grafts. Interestingly, the results showed that the harvesting method (using a trephine drill or chisel) showed no significant differences in graft stability (Bowland et al., 2020). However, preparation of the recipient site, the depth of insertion and dilation had more of an effect, showing that grafts with equal lengths to the site of insertion were more stable, and that dilation of grafts reduces the stability particularly in more skeletally immature tissue (Bowland et al., 2020). This research also highlights the importance of the underlying subchondral bone and the interrelationship between these tissues on regeneration and durability of focal defects consistent with other studies (Chan et al., 2012).

\section{Whole Joint Simulation Models to Mimic Joint Articulation}

In contrast, in vitro whole joint simulations can be used to assess the tribological performance of osteochondral grafts, taking into consideration the interactions and biomechanical properties of the joint as a whole under physiological loading conditions. These types of test are relevant for comparing the efficacy of osteochondral grafts to other surgical interventions such as scaffolds and cell-based approaches (Bowland et al., 2018b). Bowland et al. (2018a) used an adapted method from Liu et al. (2015) using a whole joint simulator with six degrees of freedom and five controlled axes of motion to mechanically test grafts. The axial load was force controlled, tibial rotation (1.6$\left.1.6^{\circ}\right)$ and flexion/extension $\left(0-21^{\circ}\right)$ were displacement controlled at a frequency of $1 \mathrm{~Hz}$. Anterior-posterior displacement was constrained using springs that generated rolling and sliding motions of the femur against the tibia, and mimicked ligament function. The medial-lateral axis was fully constrained and abduction/adduction was under passive motion. The main finding of this study was that allograft plugs fitted flush with the defect site to restore the articular surface caused the least wear and damage on the opposing joint surface after applying a complex range of motions. Similarly, Nebelung et al. (2017) combined a whole-knee joint loading device with MRI imaging to non-invasively assess the structural and functional responses of human articular osteochondral grafts in defect sites during in situ compressive loading. Whole joint simulation models highlight the importance of restoring the congruence of articular surfaces during an experimental setting that mimics more closely the physiological environment of joint articulation. However, the use of cadaveric tissue with diluted serum replicating the joint's synovial fluid is a useful approach but it fails to replicate large numbers of walking cycles due to limitations regarding the continual sterility and viability of the tissue.

\section{Shear Stress to Assess Tribology}

Chondrocytes in the superficial layer produce lubricin that maintains low coefficients of friction of joints. Maintaining a low frictional interface is essential to prevent mechanical wear and erosion of the articular surface. The application of frictional shear stress has been shown to cause damage such as cracking and peeling in cartilage TE constructs, which are not seen in native cartilage controls (Whitney et al., 2017). Therefore, assessing the tribology of osteochondral grafts is essential to ensure adequate integration and longevity. To measure the frictional coefficient, three different configurations of tribometer can be used: pinon-disc, pin-on-plate, or rolling-ball-on-disc. In the first two settings a pin is glued to the sample and a disc or a plate are in motion, while for the rolling-ball-on-disc the disc and the ball can be moved independently. In each configuration a normal force is applied and a sensor measures the frictional force, the frictional coefficient can be derived by dividing the frictional force for the normal force applied. Different types of lubricant can be used (i.e., PBS or foetal bovine serum) which combined with the different testing configurations often lead to variable results, highlighting the need of standardisation procedure to test both cartilage samples and osteochondral TE constructs. Other mechanical tests such as frictional shear stress testing can assess the tribology, pressure distribution and the response to damage of osteochondral grafts and TE constructs in whole joint models under a complex range of sliding and torsional motions (Walter et al., 2013; Bobrowitsch et al., 2014).

\section{CONCLUSIONS}

Despite tremendous advances in the field of tissue engineering, an optimal biomaterial system for osteochondral defects that is able to direct stem cell differentiation into chondrocytes for the cartilage and osteoblast for bone without the use of exogenous stimuli is elusive. Material selection is essential for creating a graft able to withstand the multiple forces that cartilage is subject to. Synthetic materials not only provide high tensile stress and compressive modulus, but they are easily modified, facilitating the creation of layered scaffolds which is a requirement for osteochondral grafts. However, the lack of cellular binding sites require them to be combined with natural materials, which are highly biocompatible and can provide biochemical cues for stem cell differentiation. The natural architecture of cartilage and the impermeable subchondral plate enhances the development of hydrostatic stress in the cartilage which promotes and maintains the chondrocytic phenotype, however few osteochondral implant designs replicate this subchondral barrier.

Although suitable mechanical properties are essential for ensuring graft stability in vivo, the optimal range of stiffnesses is yet to be determined. Conflicting results have been reported, as to whether high stiffness could enhance chondrogenic differentiation of MSCs or upregulate hypertrophic markers. The use of dynamic stimulation, such as hydrostatic pressure or dynamic loading, could promote a stable differentiation of MSCs into chondrocytes and enhance matrix deposition, thus preventing the use of TGF- $\beta$ which lead to the formation of hypertrophic cartilage.

Mechanical testing of TE constructs in vitro are essential to ensure graft stability in vivo, however, the lack of standardised procedures questions the reliability of the published data in providing an understanding of the long term endurance and 
suitability of osteochondral grafts. In addition, only a small fraction of studies on cartilage constructs tests all of the mechanical properties requested from the FDA or the ICRS and this might, in part, explain why many scaffolds fail when tested in vivo.

\section{AUTHOR CONTRIBUTIONS}

SD and TR completed a literature search, wrote the manuscript and critically revised the manuscript. MR, GB, and GT contributed ideas, content to the manuscript, and critically

\section{REFERENCES}

Abbas, Y., Carnicer-Lombarte, A., Gardner, L., Thomas, J., Brosens, J. J., Moffett, A., et al. (2019). Tissue stiffness at the human maternal-fetal interface. Human Reproduct. 34, 1999-2008. doi: 10.1093/humrep/dez139

Andriolo, L., Reale, D., Di Martino, A., De Filippis, R., Sessa, A., Zaffagnini, S., et al. (2020). Long-term results of arthroscopic matrix-assisted autologous chondrocyte transplantation: a prospective follow-up at 15 years. Am. J. Sports Med. 48, 2994-3001. doi: 10.1177/0363546520949849

Angele, P., Yoo, J. U., Smith, C., Mansour, J., Jepsen, K. J., Nerlich, M., et al. (2003). Cyclic hydrostatic pressure enhances the chondrogenic phenotype of human mesenchymal progenitor cells differentiated in vitro. J. Orthopaed. Res. 21, 451-457. doi: 10.1016/S0736-0266(02)00230-9

Angelozzi, M., Penolazzi, L., Mazzitelli, S., Lambertini, E., Lolli, A., Piva, R., et al. (2017). Dedifferentiated chondrocytes in composite microfibers as tool for cartilage repair. Front. Bioeng. Biotechnol. 5:35. doi: 10.3389/fbioe.2017.00035

Arden, N., and Nevitt, M. C. (2006). Osteoarthritis: epidemiology. Best Pract. Res. Clin. Rheumatol. 20, 3-25. doi: 10.1016/j.berh.2005.09.007

Assenmacher, A. T., Pareek, A., Reardon, P. J., Macalena, J. A., Stuart, M. J., and Krych, A. J. (2016). Long-term outcomes after osteochondral allograft: a systematic review at long-term follow-up of 12.3 years. Arthroscopy 32, 2160-2168. doi: 10.1016/j.arthro.2016.04.020

Ateshian, G. A., Chahine, N. O., Basalo, I. M., and Hung, C. T. (2004). The correspondence between equilibrium biphasic and triphasic material properties in mixture models of articular cartilage. J.Biomechan. 37, 391-400. doi: 10.1016/S0021-9290(03)00252-5

Aurich, M., Hofmann, G. O., Best, N., and Rolauffs, B. (2018). Induced redifferentiation of human chondrocytes from articular cartilage lesion in alginate bead culture after monolayer dedifferentiation: an alternative cell source for cell-based therapies? Tissue Eng. 24, 275-286. doi: 10.1089/ten.tea.2016.0505

Aziz, A. H., Eckstein, K., Ferguson, V. L., and Bryant, S. J. (2019). The effects of dynamic compressive loading on human mesenchymal stem cell osteogenesis in the stiff layer of a bilayer hydrogel. J. Tissue Eng. Regenerat. Med. 13, 946-959. doi: $10.1002 /$ term. 2827

Baba, R., Onodera, T., Matsuoka, M., Hontani, K., Joutoku, Z., Matsubara, S., et al. (2018). Bone marrow stimulation technique augmented by an ultrapurified alginate gel enhances cartilage repair in a canine model. Am. J. Sports Med. 46, 1970-1979. doi: 10.1177/0363546518770436

Baker, S. C., Rohman, G., Southgate, J., and Cameron, N. R. (2009). The relationship between the mechanical properties and cell behaviour on PLGA and PCL scaffolds for bladder tissue engineering. Biomaterials 30, 1321-1328. doi: 10.1016/j.biomaterials.2008.11.033

Barzideh, Z., Latiff, A. A., Gan, C. Y., Abedin, M. Z., and Alias, A. K. (2014). ACE inhibitory and antioxidant activities of collagen hydrolysates from the ribbon jellyfish (Chrysaora sp.). Food Tech. Biotechnol. 52, 495-504. doi: $10.17113 / \mathrm{ftb} \cdot 52.04 .14 .3641$

Baumann, C. A., Hinckel, B. B., Bozynski, C. C., and Farr, J. (2019). "Articular cartilage: structure and restoration," in Joint Preservation of the Knee, eds A. Yanke and B. Cole (Cham: Springer). doi: 10.1007/978-3-030-01491-9_1

Bayliss, L. E., Culliford, D., Monk, A. P., Glyn-Jones, S., Prieto-Alhambra, D., Judge, A., et al. (2017). The effect of patient age at intervention on risk of revised the manuscript. All authors contributed to the article and approved the submitted version.

\section{FUNDING}

This work was supported by the Faculty of Science and Health of the University of Portsmouth.

\section{ACKNOWLEDGMENTS}

All figures were created with Biorender.com.

implant revision after total replacement of the hip or knee: a population-based cohort study. Lancet 389, 1424-1430. doi: 10.1016/S0140-6736(17)30059-4

Beckwée, D., Vaes, P., Shahabpour, M., Muyldermans, R., Rommers, N., and Bautmans, I. (2015). The influence of joint loading on bone marrow lesions in the knee: a systematic review with meta-analysis. Am. J. Sports Med. 43, 3093-3107. doi: $10.1177 / 0363546514565092$

Behrens, P., Bitter, T., Kurz, B., and Russlies, M. (2006). Matrix-associated autologous chondrocyte transplantation/implantation (MACT/MACI)-5-year follow-up. Knee 13, 194-202. doi: 10.1016/j.knee.2006.02.012

Bellucci, G., and Seedhom, B. B. (2001). Mechanical behaviour of articular cartilage under tensile cyclic load, Rheumatology 40, 1337-1345. doi: 10.1093/rheumatology/40.12.1337

Bevill, S. L., Briant, P. L., Levenston, M. E., and Andriacchi, T. P. (2009). Central and peripheral region tibial plateau chondrocytes respond differently to in vitro dynamic compression. Osteoarthrit. Cartilage 17, 980-987. doi: $10.1016 /$ j.joca.2008.12.005

Bhatia, D., Bejarano, T., and Novo, M. (2013). Current interventions in the management of knee osteoarthritis. J. Pharmacy Bioallied Sci. 5:30. doi: 10.4103/0975-7406.106561

Bian, L., Zhai, D. Y., Tous, E., Rai, R., Mauck, R. L., and Burdick, J. A. (2011). Enhanced MSC chondrogenesis following delivery of TGF$\beta 3$ from alginate microspheres within hyaluronic acid hydrogels in vitro and in vivo. Biomaterials 32, 6425-6434. doi: 10.1016/j.biomaterials.2011. 05.033

Bobrowitsch, E., Lorenz, A., Jörg, J., Leichtle, U. G., Wülker, N., and Walter, C. (2014). Changes in dissipated energy and contact pressure after osteochondral graft transplantation. Med. Eng. Phys. 36. 1156-1161. doi: 10.1016/j.medengphy.2014.06.015

Bonani, W., Singhatanadgige, W., Pornanong, A., and Motta, A. (2018). "Natural Origin Materials for Osteochondral Tissue Engineering," in Osteochondral Tissue Engineering. Advances in Experimental Medicine and Biology, Vol. 1058. eds J. Oliveira, S. Pina, R. Reis, J. San Roman (Cham: Springer). doi: 10.1007/978-3-319-76711-6_1

Boschetti, F., Pennati, G., Gervaso, F., Peretti, G. M., and Dubini, G. (2004). Biomechanical properties of human articular cartilage under compressive loads. Biorheology 41, 159-166.

Boushell, M. K., Hung, C. T., Hunziker, E. B., Strauss, E. J., and Lu, H. H. (2017). Current strategies for integrative cartilage repair. Connect. Tissue Res. 58, 393-406. doi: 10.1080/03008207.2016.1231180

Bowland, P., Cowie, R. M., Ingham, E., Fisher, J., and Jennings, L. M. (2020). Biomechanical assessment of the stability of osteochondral grafts implanted in porcine and bovine femoral condyles. Proc. Inst. Mech. Eng. H. 234, 163-170. doi: $10.1177 / 0954411919891673$

Bowland, P., Ingham, E., Fisher, J., and Jennings, L. M. (2018a). Development of a preclinical natural porcine knee simulation model for the tribological assessment of osteochondral grafts in vitro. J. Biomech. 77, 91-98. doi: 10.1016/j.jbiomech.2018.06.014

Bowland, P., Ingham, E., Fisher, J., and Jennings, L. M. (2018b). Simple geometry tribological study of osteochondral graft implantation in the knee. Proc. Inst. Mech. Eng. H. 232, 249-256. doi: 10.1177/0954411917751560

Bowland, P., Ingham, E., Jennings, L., and Fisher, J. (2015). Review of the biomechanics and biotribology of osteochondral grafts used for surgical 
interventions in the knee. Proc. Insti. Mech. Eng. J. Eng. Med. 229, 879-888. doi: 10.1177/0954411915615470

Brand, R. A. (2005). Joint contact stress: a reasonable surrogate for biological processes? Iowa Orthopaed. J. 25, 82-94.

Brandao, B., Aljawadi, A., Hall, A., Fox, A., and Pillai, A. (2020). Cartiva case series: the efficacy of the cartiva synthetic cartilage implant interpositional arthroplasty at one year. J. Orthopaed. 20, 338-341. doi: 10.1016/j.jor.2020.05.009

Briant, P., Bevill, S., and Andriacchi, T. (2015). Cartilage strain distributions are different under the same load in the central and peripheral tibial plateau regions. J. Biomech. Eng. 137:121009. doi: 10.1115/1.4031849

Brittberg, M., Lindahl, A., Nilsson, A., Ohlsson, C., Isaksson, O., and Peterson, L. (1994). Treatment of deep cartilage defects in the knee with autologous chondrocyte transplantation. N. Engl. J. Med. 331, 889-895. doi: 10.1056/NEJM199410063311401

Brown, T. D., Pope, D. F., Hale, J. E., Buckwalter, J. A., and Brand, R. A. (1991). Effects of osteochondral defect size on cartilage contact stress. J. Orthop. Res.9, 559-567. doi: 10.1002/jor.1100090412

Bryant, S. J., and Anseth, K. S. (2002). Hydrogel properties influence ECM production by chondrocytes photoencapsulated in poly(ethylene glycol) hydrogels. J. Biomed. Mater. Res. 59, 63-72. doi: 10.1002/jbm.1217

Buckwalter, J. A., Anderson, D. D., Brown, T. D., Tochigi, Y., and Martin, J. A. (2013). The roles of mechanical stresses in the pathogenesis of osteoarthritis: implications for treatment of joint injuries. Cartilage 4, 286-294. doi: $10.1177 / 1947603513495889$

Buschmann, M. D., Kim, Y. J., Wong, M., Frank, E., Hunziker, E. B., and Grodzinsky, A. J. (1999). Stimulation of aggrecan synthesis in cartilage explants by cyclic loading is localized to regions of high interstitial fluid flow. Arch. Biochem. Biophys. 366, 1-7. doi: 10.1006/abbi.1999.1197

Calabrese, G., Forte, S., Gulino, R., Cefal,ì, F., Figallo, E., Salvatorelli, L., et al. (2017a). Combination of collagen-based scaffold and bioactive factors induces adipose-derived mesenchymal stem cells chondrogenic differentiation in vitro. Front. Physiol. 8:50. doi: 10.3389/fphys.2017.00050

Calabrese, G., Gulino, R., Giuffrida, R., Forte, S., Figallo, E., Fabbi, C., et al. (2017b). In vivo evaluation of biocompatibility and chondrogenic potential of a cell-free collagen-based scaffold. Front. Physiol. 8:984. doi: 10.3389/fphys.2017.00984

Cao, W., Lin, W., Cai, H., Chen, Y., Man, Y., Liang, J., et al. (2019). Dynamic mechanical loading facilitated chondrogenic differentiation of rabbit BMSCs in collagen scaffolds. Regenerat. Biomater. 6, 99-106. doi: 10.1093/rb/r bz005

Caron, M. M., Emans, P. J., Coolsen, M. M., Voss, L., Surtel, D. A., Cremers, A., et al. (2012). Redifferentiation of dedifferentiated human articular chondrocytes: comparison of 2D and 3D cultures. Osteoarthritis Cartilage 20, 1170-1178. doi: 10.1016/j.joca.2012.06.016

Castilho, M., Hochleitner, G., Wilson, W., van Rietbergen, B., Dalton, P. D., Groll, J., et al. (2018). Mechanical behavior of a soft hydrogel reinforced with three-dimensional printed microfibre scaffolds. Sci. Rep. 8:1245. doi: 10.1038/s41598-01819502-y

Castilho, M., Mouser, V., Chen, M., Malda, J., and Ito, K. (2019). Bi-layered micro-fibre reinforced hydrogels for articular cartilage regeneration. Acta Biomaterialia 95, 297-306. doi: 10.1016/j.actbio.2019.06.030

Catoira, M. C., Fusaro, L., Di Francesco, D., Ramella, M., and Boccafoschi, F. (2019). Overview of natural hydrogels for regenerative medicine applications. J. Mater. Sci. 30:115. doi: 10.1007/s10856-019-6318-7

Chan, D. D., Cai, L., Butz, K. D., Trippel, S. B., Nauman, E. A., and Neu, C. P. (2016). In vivo articular cartilage deformation: noninvasive quantification of intratissue strain during joint contact in the human knee. Sci. Rep. 6:19220. doi: $10.1038 /$ srep 19220

Chan, E. F., Liu, I. L., Semler, E. J., Aberman, H. M., Simon, T. M., Chen, A. C., et al. (2012). Association of 3-dimensional cartilage and bone structure with articular cartilage properties in and adjacent to autologous osteochondral grafts after 6 and 12 months in a Goat Model. Cartilage 3, 255-266. doi: $10.1177 / 1947603511435272$

Chang, S. H., Mori, D., Kobayashi, H., Mori, Y., Nakamoto, H., Okada, K., et al. (2019). Excessive mechanical loading promotes osteoarthritis through the gremlin-1-NF-kB pathway. Nat. Commun. 10:1442. doi: 10.1038/s41467-019-09491-5
Chen, C. H., Kuo, C. Y., Wang, Y. J., and Chen, J. P. (2016). Dual function of glucosamine in gelatin/hyaluronic acid cryogel to modulate scaffold mechanical properties and to maintain chondrogenic phenotype for cartilage tissue engineering. Int. J. Mol. Sci. 17:1957. doi: 10.3390/ijms17111957

Chen, C. T., Burton-Wurster, N., Borden, C., Hueffer, K., Bloom, S. E., and Lust, G. (2001). Chondrocyte necrosis and apoptosis in impact damaged articular cartilage. J. Orthopaed. Res. 19, 703-711. doi: 10.1016/S0736-0266(00)00066-8

Chen, S., Zhang, Q., Nakamoto, T., Kawazoe, N., and Chen, G. (2016). Gelatin scaffolds with controlled pore structure and mechanical property for cartilage tissue engineering. Tissue Eng. 22, 189-198. doi: 10.1089/ten.tec.2015.0281

Chen, Z., Zhong, N., Wen, J., Jia, M., Guo, Y., Shao, Z., et al. (2018). Porous three-dimensional silk fibroin scaffolds for tracheal epithelial regeneration in vitro and in vivo. ACS Biomater. Sci. Eng. 4, 2977-2985. doi: 10.1021 /acsbiomaterials.8b00419

Cheung, R. C., Ng, T. B., Wong, J. H., and Chan, W. Y. (2015). Chitosan: an update on potential biomedical and pharmaceutical applications. Marine Drugs 13, 5156-5186. doi: 10.3390/md13085156

Chowdhury, T. T., Bader, D. L., and Lee, D. A. (2001). Dynamic compression inhibits the synthesis of nitric oxide and PGE(2) by IL-1beta-stimulated chondrocytes cultured in agarose constructs. Biochem. Biophys. Res. Commun. 285, 1168-1174. doi: 10.1006/bbrc.2001.5311

Chu, C. R., Szczodry, M., and Bruno, S. (2010). Animal models for cartilage regeneration and repair. Tissue Eng. Part B Rev. 16, 105-115. doi: $10.1089 /$ ten.teb.2009.0452

Chu, G., Yuan, Z., Zhu, C., Zhou, P., Wang, H., Zhang, W., et al. (2019). Substrate stiffness- and topography-dependent differentiation of annulus fibrosusderived stem cells is regulated by Yes-associated protein. Acta Biomaterial. 92, 254-264. doi: 10.1016/j.actbio.2019.05.013

Clements, K., Bee, Z., Crossingham, G., Adams, M., and Sharif., M (2001). How severe must repetitive loading be to kill chondrocytes in articular cartilage? Osteoarthrit. Cartilage 9, 499-507. doi: 10.1053/joca.2000.0417

Clements, K. M., Hollander, A. P., Sharif, M., and Adams, M. A. (2004). Cyclic loading can denature type II collagen in articular cartilage. Connect Tissue Res. 45, 174-180. doi: 10.1080/03008200490514121

Coleman, J. L., Widmyer, M. R., Leddy, H. A., Utturkar, G. M., Spritzer, C. E., Moorman, C. T. III, et al. (2013). Diurnal variations in articular cartilage thickness and strain in the human knee. J. Biomechan. 46, 541-547. doi: 10.1016/j.jbiomech.2012.09.013

Coluccino, L., Stagnaro, P., Vassalli, M., and Scaglione, S. (2016). Bioactive TGF- $\beta 1 / \mathrm{HA}$ alginate-based scaffolds for osteochondral tissue repair: design, realization and multilevel characterization. J. Appl. Biomater. Funct. Mater. 14, e42-e52. doi: 10.5301/jabfm.5000249

Coricor, G., and Serra, R. (2016). TGF- $\beta$ regulates phosphorylation and stabilization of Sox9 protein in chondrocytes through p38 and Smad dependent mechanisms. Sci. Rep. 6:38616. doi: 10.1038/srep38616

Correa, D., and Lietman, S. A. (2017). Articular cartilage repair: current needs, methods and research directions. Semin. Cell Dev. Biol., 62, 67-77. doi: 10.1016/j.semcdb.2016.07.013

Correia, C., Pereira, A. L., Duarte, A. R., Frias, A. M., Pedro, A. J., Oliveira, J. T., et al. (2012). Dynamic culturing of cartilage tissue: the significance of hydrostatic pressure. Tissue Eng. 18, 1979-1991. doi: 10.1089/ten.tea.2012.0083

Cotofana, S., Eckstein, F., Wirth, W., Souza, R. B., Li, X., Wyman, B., et al. (2011). In vivo measures of cartilage deformation: patterns in healthy and osteoarthritic female knees using 3T MR imaging. Eur. Radiol. 21, 1127-1135. doi: 10.1007/s00330-011-2057-y

Crawford, D. C., DeBerardino, T. M., and Williams, R. J. III (2012). NeoCart, an autologous cartilage tissue implant, compared with microfracture for treatment of distal femoral cartilage lesions: an FDA phase-II prospective, randomized clinical trial after two years. J. Bone Joint Surgery 94, 979-989. doi: 10.2106/JBJS.K.00533

Critchley, S., Sheehy, E. J., Cunniffe, G., Diaz-Payno, P., Carroll, S. F., Jeon, O., et al. (2020). 3D printing of fibre-reinforced cartilaginous templates for the regeneration of osteochondral defects. Acta Biomaterial. S1742-7061(20)303196. doi: 10.1016/j.actbio.2020.05.040

Dai, Y., Shen, T., Ma, L., Wang, D., and Gao, C. (2018). Regeneration of osteochondral defects in vivo by a cell-free cylindrical poly(lactide-coglycolide) scaffold with a radially oriented microstructure. J. Tissue Eng. Regenerat. Med. 12, e1647-e1661. doi: 10.1002/term.2592 
D’Ambrosi, R., Valli, F., De Luca, P., Ursino, N., and Usuelli, F. G. (2019). MaioRegen osteochondral substitute for the treatment of knee defects: a systematic review of the literature. J. Clin. Med. 8:783. doi: 10.3390/jcm8060783

d'Angelo, M., Benedetti, E., Tupone, M. G., Catanesi, M., Castelli, V., Antonosante, A., et al. (2019). The role of stiffness in cell reprogramming: a potential role for biomaterials in inducing tissue regeneration. Cells 8:1036. doi: $10.3390 /$ cells 8091036

Davies, R. L., and Kuiper, N. J. (2019). Regenerative medicine: a review of the evolution of autologous chondrocyte implantation (ACI) Therapy. Bioengineering 6:22. doi: 10.3390/bioengineering6010022

De Mori, A., Hafidh, M., Mele, N., Yusuf, R., Cerri, G., Gavini, E., et al. (2019). Sustained release from injectable composite gels loaded with silver nanowires designed to combat bacterial resistance in bone regeneration applications. Pharmaceutics 11:116. doi: 10.3390/pharmaceutics11030116

D’Lima, D. D., Hashimoto, S., Chen, P. C., Colwell, C. W. Jr, and Lotz, M. K. (2001). Human chondrocyte apoptosis in response to mechanical injury. Osteoarthritis Cartilage 9, 712-719. doi: 10.1053/joca.2001.0468

Donell, S. (2019). Subchondral bone remodelling in osteoarthritis. EFORT Open Rev. 4, 221-229. doi: 10.1302/2058-5241.4.180102

Dong, C., and Lv, Y. (2016). Application of collagen scaffold in tissue engineering: recent advances and new perspectives. Polymers 8:42. doi: 10.3390/polym8020042

Du, J., Zu, Y., Li, J., Du, S., Xu, Y., Zhang, L., et al. (2016). Extracellular matrix stiffness dictates Wnt expression through integrin pathway. Sci. Rep. 6:20395. doi: 10.1038/srep20395

Ehrbar, M., Sala, A., Lienemann, P., Ranga, A., Mosiewicz, K., Bittermann, A., et al. (2011). Elucidating the role of matrix stiffness in 3D cell migration and remodeling. Biophys. J. 100, 284-293. doi: 10.1016/j.bpj.2010.11.082

Elder, B. D., and Athanasiou, K. A. (2009). Hydrostatic pressure in articular cartilage tissue engineering: from chondrocytes to tissue regeneration. Tissue Eng. 15, 43-53. doi: 10.1089/ten.teb.2008.0435

Elder, S., Gottipati, A., Zelenka, H., and Bumgardner, J. (2013). Attachment, proliferation, and chondroinduction of mesenchymal stem cells on porous chitosan-calcium phosphate scaffolds. Open Orthopaed. J. 7, 275-281. doi: 10.2174/1874325001307010275

Engler, A. J., Sen, S., Sweeney, H. L., and Discher, D. E. (2006). Matrix elasticity directs stem cell lineage specification. Cell 126, 677-689. doi: 10.1016/j.cell.2006.06.044

Erggelet, C., and Vavken, P. (2016). Microfracture for the treatment of cartilage defects in the knee joint - a golden standard? J. Clin. Orthop. Trauma. 7, 145-152. doi: 10.1016/j.jcot.2016.06.015

Eriksen, E. F. (2015). Treatment of bone marrow lesions (bone marrow edema). BoneKEy Rep. 4:755. doi: 10.1038/bonekey.2015.124

Evans, J. T., Evans, J. P., Walker, R. W., Blom, A. W., Whitehouse, M. R., and Sayers, A. (2019). How long does a hip replacement last? A systematic review and meta-analysis of case series and national registry reports with more than 15 years of follow-up. Lancet 393, 647-654. doi: 10.1016/S0140-6736(18) 31665-9

Ewa-Choy, Y. W., Pingguan-Murphy, B., Abdul-Ghani, N. A., Jahendran, J., and Chua, K. H. (2017). Effect of alginate concentration on chondrogenesis of cocultured human adipose-derived stem cells and nasal chondrocytes: a biological study. Biomater. Res. 21:19. doi: 10.1186/s40824-017-0105-7

Faikrua, A., Wittaya-areekul, S., Oonkhanond, B., and Viyoch, J. (2013). In vivo chondrocyte and transforming growth factor- $\beta 1$ delivery using the thermosensitive chitosan/starch/ $\beta$-glycerol phosphate hydrogel. J. Biomater. Appl. 28, 175-186. doi: 10.1177/0885328212441847

Familiari, F., Cinque, M. E., Chahla, J., Godin, J. A., Olesen, M. L., Moatshe, G., et al. (2018). Clinical outcomes and failure rates of osteochondral allograft transplantation in the knee: a systematic review. Am. J. Sports Med. 46, 3541-3549. doi: 10.1177/0363546517732531

Félix Lanao, R. P., Jonker, A. M., Wolke, J. G., Jansen, J. A., van Hest, J. C., and Leeuwenburgh, S. C. (2013). Physicochemical properties and applications of poly(lactic-co-glycolic acid) for use in bone regeneration. Tissue Eng. 19, 380-390. doi: 10.1089/ten.teb.2012.0443

Fisher, M., Ackley, T., Richard, K., Oei, B., and Dealy, C. N. (2019). Osteoarthritis at the Cellular Level: Mechanisms, Clinical Perspectives, and Insights From Development. Reference Module in Biomedical Sciences Encyclopedia of Biomedical Engineering. Amsterdam: Elsevier, 660-676.
Fraser, E. J., Savage-Elliott, I., Yasui, Y., Ackermann, J., Watson, G., Ross, K. A., et al. (2016). Clinical and MRI donor site outcomes following autologous osteochondral transplantation for talar osteochondral lesions. Foot Ankle Int. 37, 968-976. doi: 10.1177/1071100716649461

Freeman, F. E., Schiavi, J., Brennan, M. A., Owens, P., Layrolle, P., and McNamara, L. M. (2017). * Mimicking the biochemical and mechanical extracellular environment of the endochondral ossification process to enhance the in vitro mineralization potential of human mesenchymal stem cells. Tissue Eng. Part A, 23, 1466-1478. doi: 10.1089/ten.tea.2017.0052

Freitag, J., Shah, K., Wickham, J., Boyd, R., and Tenen, A. (2017). The effect of autologous adipose derived mesenchymal stem cell therapy in the treatment of a large osteochondral defect of the knee following unsuccessful surgical intervention of osteochondritis dissecans - a case study. BMC Musculoskeletal Disord. 18:298. doi: 10.1186/s12891-017-1658-2

Frisbie, D. D., Cross, M. W., and McIlwraith, C. W. (2006). A comparative study of articular cartilage thickness in the stifle of animal species used in human pre-clinical studies compared to articular cartilage thickness in the human knee. Vet. Comparat. Orthopaed. Traumatol. 19, 142-146. doi: 10.1055/s-0038-1632990

Fu, S., Thompson, C. L., Ali, A., Wang, W., Chapple, J.P., Mitchison, H. M., et al. (2019). Mechanical loading inhibits cartilage inflammatory signalling via an HDAC6 and IFT-dependent mechanism regulating primary cilia elongation. Osteoarthritis Cartilage 27, 1064-1074. doi: 10.1016/j.joca.2019.03.003

Furumatsu, T., Ozaki, T., and Asahara, H. (2009). Smad3 activates the Sox9dependent transcription on chromatin. Int. J. Biochem. Cell Biol. 41, 1198-1204. doi: 10.1016/j.biocel.2008.10.032

Gan, D., Xu, T., Xing, W., Wang, M., Fang, J., Wang, K., et al. (2019). Mussel-inspired dopamine oligomer intercalated tough and resilient gelatin methacryloyl (GelMA) hydrogels for cartilage regeneration. J. Mater. Chem. 7, 1716-1725. doi: 10.1039/C8TB01664J

Ganesh, N., Hanna, C., Nair, S. V., and Nair, L. S. (2013). Enzymatically crosslinked alginic-hyaluronic acid composite hydrogels as cell delivery vehicles. Int. J. Biol. Macromolecules 55, 289-294. doi: 10.1016/j.ijbiomac.2012.12.045

Gardner, O., Fahy, N., Alini, M., and Stoddart, M. J. (2017). Joint mimicking mechanical load activates TGF $\beta 1$ in fibrin-poly(ester-urethane) scaffolds seeded with mesenchymal stem cells. J. Tissue Eng. Regenerative Med. 11, 2663-2666. doi: 10.1002/term.2210

Gentile, P., Chiono, V., Carmagnola, I., and Hatton, P. V. (2014). An overview of poly(lactic-co-glycolic) acid (PLGA)-based biomaterials for bone tissue engineering. In. J. Mol. Sci. 15, 3640-3659. doi: 10.3390/ijms15033640

Ghodbane, S. A., and Dunn, M. G. (2016). Physical and mechanical properties of cross-linked type I collagen scaffolds derived from bovine, porcine, and ovine tendons. J. Biomed. Mater. Re. Part A, 104, 2685-2692. doi: $10.1002 /$ jbm.a.35813

Gilbert, S. J., and Blain, E. J. (2018). “Cartilage mechanobiology: how chondrocytes respond to mechanical load," in Mechanobiology in Health and Disease, ed S. Verbruggen, Mechanobiology in Health and Disease (Elsevier), 99-126. doi: 10.1016/B978-0-12-812952-4.00004-0

Gorth, D., and Webster, T. J. (2011). 10-Matrices for Tissue Engineering and Regenerative Medicine Biomaterials for Artificial Organs, Woodhead Publishing Series in Biomaterials, ed M. L. J. Webster. Sawston: Woodhead Publishing, 270-286.

Griffin, M., Premakumar, Y., Seifalian, A., Butler, P. E., and Szarko, M. (2016). Biomechanical characterization of human soft tissues using indentation and tensile testing. J. Visualized Exp. 118:54872. doi: 10.3791/54872

Griffon, D. J., Sedighi, M. R., Schaeffer, D. V., Eurell, J. A., and Johnson, A. L. (2006). Chitosan scaffolds: interconnective pore size and cartilage engineering. Acta Biomaterial. 2, 313-320. doi: 10.1016/j.actbio.2005.12.007

Grigore, M. E. (2017). Biomaterials for cartilage tissue engineering. J. Tiss. Sci. Eng. 8, 4-9. doi: 10.4172/2157-7552.1000192

Grimm, N. L., Weiss, J. M., Kessler, J. I., and Aoki, S. K. (2014). Osteochondritis dissecans of the knee: pathoanatomy, epidemiology, and diagnosis. Clin. Sports Med. 33, 181-188. doi: 10.1016/j.csm.2013.11.006

Grover, C. N., Gwynne, J. H., Pugh, N., Hamaia, S., Farndale, R. W., Best, S. M., et al. (2012). Crosslinking and composition influence the surface properties, mechanical stiffness and cell reactivity of collagenbased films. Acta Biomaterial. 8, 3080-3090. doi: 10.1016/j.actbio.2012. 05.006 
Gu, W. Y., Lai, W. M., and Mow, V. C. (1998). A mixture theory for chargedhydrated soft tissues containing multi-electrolytes: passive transport and swelling behaviors. J. Biomechan. Eng. 120, 169-180. doi: 10.1115/1.2798299

Guimarães, C. F., Gasperini, L., Marques, A. P., and Reis, L. R. (2020). The stiffness of living tissues and its implications for tissue engineering. Nat. Rev. Mater. 5, 351-370 doi: 10.1038/s41578-019-0169-1

Gunatillake, P. A., and Adhikari, R. (2003). Biodegradable synthetic polymers for tissue engineering. Eur. Cells Mater. 5, 1-16. doi: 10.22203/eCM.v005a01

Haber, D. B., Logan, C. A., Murphy, C. P., Sanchez, A., LaPrade, R. F., and Provencher, M. T. (2019). Osteochondral allograft transplantation for the knee: post-operative rehabilitation. Int. J. Sports Phys. Ther. 14, 487-499. doi: $10.26603 /$ ijspt20190487

Halonen, K. S., Mononen, M. E., Jurvelin, J. S., Töyräs, J., Salo, J., and Korhonen, R. K. (2014). Deformation of articular cartilage during static loading of a knee joint - Experimental and finite element analysis. J. Biomechan. 47, 2467-2474. doi: 10.1016/j.jbiomech.2014.04.013

Handorf, A. M., Zhou, Y., Halanski, M. A., and Li, W. J. (2015). Tissue stiffness dictates development, homeostasis, and disease progression. Organogenesis 11, 1-15. doi: 10.1080/15476278.2015.1019687

Hemmati-Sadeghi, S., Ringe, J., Dehne, T., Haag, R., and Sittinger, M. (2018). Hyaluronic acid influence on normal and osteoarthritic tissue-engineered cartilage. Int. J. Mol. Sci. 19:1519. doi: 10.3390/ijms19051519

Henrionnet, C., Liang, G., Roeder, E., Dossot, M., Wang, H., Magdalou, J., et al. (2017). * Hypoxia for mesenchymal stem cell expansion and differentiation: the best way for enhancing TGFß-induced chondrogenesis and preventing calcifications in alginate beads. Tissue Eng. 23, 913-922. doi: $10.1089 /$ ten.tea.2016.0426

Holloway, J. L., Spiller, K. L., Lowman, A. M., and Palmese, G. R. (2011). Analysis of the in vitro swelling behavior of poly(vinyl alcohol) hydrogels in osmotic pressure solution for soft tissue replacement. Acta Biomaterial. 7, 2477-2482. doi: 10.1016/j.actbio.2011.02.016

Homicz, M. R., Chia, S. H., Schumacher, B. L., Masuda, K., Thonar, E. J., Sah, R. L., et al. (2003). Human septal chondrocyte redifferentiation in alginate, polyglycolic acid scaffold, and monolayer culture. Laryngoscope 113, 25-32. doi: 10.1097/00005537-200301000-00005

Hosseini, S. M., Wilson, W., Ito, K., and Van Donkelaar, C. C. (2014). A numerical model to study mechanically induced initiation and progression of damage in articular cartilage. Osteoarthr. Cartil. 22, 95-103. doi: $10.1016 /$ j.joca.2013.10.010

Houard, X., Goldring, M. B., and Berenbaum, F. (2013). Homeostatic mechanisms in articular cartilage and role of inflammation in osteoarthritis. Curr. Rheumatol. Rep. 15:375. doi: 10.1007/s11926-013-0375-6

Hu, W., Chen, Y., Dou, C., and Dong, S. (2020). Microenvironment in Subchondral Bone: Predominant Regulator for the Treatment of Osteoarthritis. Annals of the rheumatic diseases, annrheumdis-2020-218089. Advance online publication. doi: 10.1136/annrheumdis-2020-218089

Huang, C. Y., Stankiewicz, A., Ateshian, G. A., and Mow, V. C. (2005). Anisotropy, inhomogeneity, and tension-compression nonlinearity of human glenohumeral cartilage in finite deformation. J. Biomechan. 38, 799-809. doi: 10.1016/j.jbiomech.2004.05.006

Huang, Y., Seitz, D., König, F., Müller, P. E., Jansson, V., and Klar, R. M. (2019). Induction of articular chondrogenesis by chitosan/hyaluronic-acid-based biomimetic matrices using human adipose-derived stem cells. Int. J. Mol. Sci. 20:4487. doi: 10.3390/ijms20 184487

Huang, Z., Nooeaid, P., Kohl, B., Roether, J. A., Schubert, D. W., Meier, C., et al. (2015). Chondrogenesis of human bone marrow mesenchymal stromal cells in highly porous alginate-foams supplemented with chondroitin sulfate. Mater. Sci. Eng. 50, 160-172. doi: 10.1016/j.msec.2015.01.082

Hunter, D., Schofield, D., and Callander, E. (2014). The individual and socioeconomic impact of osteoarthritis. Nat. Rev. Rheumatol. 10, 437-441. doi: 10.1038/nrrheum.2014.44

Hunter, D. J., Gerstenfeld, L., Bishop, G., Davis, A. D., Mason, Z. D., Einhorn, T. A., et al. (2009). Bone marrow lesions from osteoarthritis knees are characterized by sclerotic bone that is less well mineralized. Arthrit. Res. Therapy 11:R11. doi: 10.1186/ar2601

Hurtig, M. B., Buschmann, M. D., Fortier, L. A., Hoemann, C. D., Hunziker, E. B., Jurvelin, J. S., et al. (2011). Preclinical studies for cartilage repair: recommendations from the international cartilage repair society. Cartilage 2, 137-152. doi: 10.1177/1947603511401905

Hwang, J., Bae, W. C., Shieu, W., Lewis, C. W., Bugbee, W. D., and Sah, R. L. (2008). Increased hydraulic conductance of human articular cartilage and subchondral bone plate with progression of osteoarthritis. Arthritis Rheumat. 58, 3831-3842. doi: 10.1002/art.24069

Hwang, J. H., Byun, M. R., Kim, A. R., Kim, K. M., Cho, H. J., Lee, Y. H., et al. (2015). Extracellular matrix stiffness regulates osteogenic differentiation through MAPK activation. PLoS ONE 10:e0135519. doi: 10.1371/journal.pone.0135519

Iseki, T., Rothrauff, B. B., Kihara, S., Sasaki, H., Yoshiya, S., Fu, F. H., et al. (2019). Dynamic compressive loading improves cartilage repair in an in vitro model of microfracture: comparison of 2 mechanical loading regimens on simulated microfracture based on fibrin gel scaffolds encapsulating connective tissue progenitor cells. Am. J. Sports Med. 47, 2188-2199. doi: $10.1177 / 0363546519855645$

Jahr, H. (2017). "Tissue engineering strategies for cartilage repair," in Cartilage, eds S. Grässel and A. Aszódi (Cham: Springer). doi: 10.1007/978-3-319-53316-2_10

Jeuken, R. M., Roth, A. K., Peters, R., Van Donkelaar, C. C., Thies, J. C., Van Rhijn, L. W., et al. (2016). Polymers in cartilage defect repair of the knee: current status and future prospects. Polymers 8:219. doi: 10.3390/polym8060219

Joshi, N., Reverte-Vinaixa, M., Díaz-Ferreiro, E. W., and Domínguez-Oronoz, R. (2012). Synthetic resorbable scaffolds for the treatment of isolated patellofemoral cartilage defects in young patients: magnetic resonance imaging and clinical evaluation. Am. J. Sports Med. 40, 1289-1295. doi: $10.1177 / 0363546512441585$

Jurvelin, J., Kiviranta, I., Tammi, M., and Helminen, J. H. (1986). Softening of canine articular cartilage after immobilization of the knee joint. Clin. Orthop. Relat. Res. 207, 246-252. doi: 10.1097/00003086-198606000-00042

Kaklamani, G., Cheneler, D., Grover, L. M., Adams, M. J., and Bowen, J. (2014). Mechanical properties of alginate hydrogels manufactured using external gelation. J. Mech. Behav. Biomed. Mater. 36, 135-142. doi: 10.1016/j.jmbbm.2014.04.013

Karimi, A., and Navidbakhsh, M. (2014). Mechanical properties of PVA material for tissue engineering applications. Mater. Technol. 29:2, 90-100. doi: 10.1179/1753555713Y.0000000115

Kato, Y., Chavez, J., Yamada, S., Hattori, S., Takazawa, S., and Ohuchi, H. (2018). A large knee osteochondral lesion treated using a combination of osteochondral autograft transfer and second-generation autologous chondrocyte implantation: a case report. Regenerat. Ther. 10, 10-16. doi: $10.1016 /$ j.reth.2018.10.002

Kempson, G. E., Muir, H., Pollard, C., and Tuke, M. (1973). The tensile properties of the cartilage of human femoral condyles related to the content of collagen and glycosaminoglycans. Biochim. Biophys. Acta 297, 456-472. doi: 10.1016/0304-4165(73)90093-7

Keong, L. C., and Halim, A. S. (2009). In vitro models in biocompatibility assessment for biomedical-grade chitosan derivatives in wound management. Int. J. Mol. Sci. 10, 1300-1313. doi: 10.3390/ijms10031300

Kerin, A. J., Wisnom, M. R., and Adams, M. A. (1998). The compressive strength of articular cartilage. Proc. Inst. Mech. Eng. H 212, 273-280. doi: 10.1243/0954411981534051

Kleemann, R. U., Krocker, D., Cedraro, A., Tuischer, J., and Duda, G. N. (2005). Altered cartilage mechanics and histology in knee osteoarthritis: relation to clinical assessment (ICRS Grade). Osteoarthrit. Cartilage 13, 958-963. doi: 10.1016/j.joca.2005.06.008

Klotz, B. J., Gawlitta, D., Rosenberg, A., Malda, J., and Melchels, F. (2016). Gelatinmethacryloyl hydrogels: towards biofabrication-based tissue repair. Trends Biotechnol. 34, 394-407. doi: 10.1016/j.tibtech.2016.01.002

Kock, N. B., Smolders, J. M., van Susante, J. L., Buma, P., van Kampen, A., and Verdonschot, N. (2008). A cadaveric analysis of contact stress restoration after osteochondral transplantation of a cylindrical cartilage defect. Knee Surg Sports Traumatol Arthrosc. 16, 461-468. doi: 10.1007/s00167-008-0494-1

Kock, N. B., Van Susante, J. L., Buma, P., Van Kampen, A., and Verdonschot, N. (2006). Press-fit stability of an osteochondral autograft: influence of different plug length and perfect depth alignment. Acta Orthop. 77, 422-428. doi: 10.1080/17453670610046352

Koh, J. L., Wirsing, K., Lautenschlager, E., and Zhang, L. O. (2004). The effect of graft height mismatch on contact pressure following osteochondral 
grafting: a biomechanical study. Am. J. Sports Med. 32, 317-320. doi: $10.1177 / 0363546503261730$

Koh, L. D., Cheng, Y., Teng, C. P., Khin, Y. W., Loh, X. J., Tee, S. Y., et al. (2015). Structures, mechanical properties and applications of silk fibroin materials. In Progress in Polymer Science. 46, 86-110. doi: 10.1016/j.progpolymsci.2015.02.001

Komeili,A., Abusara, Z., Federico, S., and Herzog, W. (2019). Effect of strain rate on transient local strain variations in articular cartilage. J. Mech. Behav. Biomed. Mater. 95, 60-66. doi: 10.1016/j.jmbbm.2019.03.022

Kon, E., Delcogliano, M., Filardo, G., Altadonna, G., and Marcacci, M. (2009). Novel nano-composite multi-layered biomaterial for the treatment of multifocal degenerative cartilage lesions. Knee Surgery Sports Traumatol. Arthroscopy 17, 1312-1315. doi: 10.1007/s00167-009-0819-8

Könst, Y. E., Benink, R. J., Veldstra, R., van der Krieke, T. J., Helder, M. N., and van Royen, B. J. (2012). Treatment of severe osteochondral defects of the knee by combined autologous bone grafting and autologous chondrocyte implantation using fibrin gel. Knee Surgery Sports Traumatol Arthroscopy 20, 2263-2269. doi: 10.1007/s00167-012-1891-z

Korhonen, R. K., Laasanen, M. S., Töyräs, J., Rieppo, J., Hirvonen, J., Helminen, H. J., et al. (2002). Comparison of the equilibrium response of articular cartilage in unconfined compression, confined compression and indentation. J. Biomechan. 35, 903-909. doi: 10.1016/S0021-9290(02)00052-0

Krasnokutsky, S., Belitskaya-Lévy, I., Bencardino, J., Samuels, J., Attur, M., Regatte, R., et al. (2011). Quantitative magnetic resonance imaging evidence of synovial proliferation is associated with radiographic severity of knee osteoarthritis. Arthritis Rheumat. 63, 2983-2991. doi: 10.1002/art. 30471

Kudva, A. K., Luyten, F. P., and Patterson, J. (2018). In vitro screening of molecularly engineered polyethylene glycol hydrogels for cartilage tissue engineering using periosteum-derived and ATDC5 cells. Int. J. Mol. Sci. 19:3341. doi: 10.3390/ijms19113341

Kundanati, L., Singh, S. K., Mandal, B. B., Murthy, T. G., Gundiah, N., and Pugno, N. M. (2016). Fabrication and mechanical characterization of hydrogel infused network silk scaffolds. Int. J. Mol. Sci. 17:1631. doi: 10.3390/ijms17 101631

Kusmono, and Abdurrahim, I. (2019). Water sorption, antimicrobial activity, and thermal and mechanical properties of chitosan/clay/glycerol nanocomposite films. Heliyon 5:e02342. doi: 10.1016/j.heliyon.2019.e02342

Lai, W. M., Hou, J. S., and Mow, V. C. (1991). A triphasic theory for the swelling and deformation behaviors of articular cartilage. J. Biomechan. Eng. 113, 245-258. doi: 10.1115/1.2894880

Langasco, R., Cadeddu, B., Formato, M., Lepedda, A. J., Cossu, M., Giunchedi, P., et al. (2017). Natural collagenic skeleton of marine sponges in pharmaceutics: Innovative biomaterial for topical drug delivery. Mater. Sci. Eng. 70(Pt 1), 710-720. doi: 10.1016/j.msec.2016.09.041

Leddy, H. A., Christensen, S. E., and Guilak, F. (2008). Microscale diffusion properties of the cartilage pericellular matrix measured using 3D scanning microphotolysis. J. Biomechan. Eng. 130:061002. doi: 10.1115/1.2979876

Lee, H. Y., Hwang, C. H., Kim, H. E., and Jeong, S. H. (2018). Enhancement of bio-stability and mechanical properties of hyaluronic acid hydrogels by tannic acid treatment. Carbohydrate Polymers 186, 290-298. doi: 10.1016/j.carbpol.2018.01.056

Lee, K. Y., and Mooney, D. J. (2012). Alginate: properties and biomedical applications. Progr. Polymer Sci. 37, 106-126. doi: 10.1016/j.progpolymsci.2011.06.003

Leong, D. J., Li, Y. H., Gu, X. I., Sun, L., Zhou, Z., Nasser, P., et al. (2011). Physiological loading of joints prevents cartilage degradation through CITED2. FASEB J. 25, 182-191. doi: 10.1096/fj.10-164277

Levett, P. A., Hutmacher, D. W., Malda, J., and Klein, T. J. (2014). Hyaluronic acid enhances the mechanical properties of tissue-engineered cartilage constructs. PLoS ONE 9:e113216. doi: 10.1371/journal.pone.0113216

Li, G., Yin, J., Gao, J., Cheng, T. S., Pavlos, N. J., Zhang, C., et al. (2013). Subchondral bone in osteoarthritis: insight into risk factors and microstructural changes. Arthritis Res. Therapy 15:223. doi: 10.1186/ar4405

Li, J. J., Kim, K., Roohani-Esfahani, S. I., Guo, J., Kaplan, D. L., and Zreiqat, H. (2015). A biphasic scaffold based on silk and bioactive ceramic with stratified properties for osteochondral tissue regeneration. J. Materials Chem. B 3, 5361-5376. doi: 10.1039/С5TB00353A
Li, L., Duan, X., Fan, Z., Chen, L., Xing, F., Xu, Z., et al. (2018a). Mesenchymal stem cells in combination with hyaluronic acid for articular cartilage defects. Sci. Rep. 8:9900. doi: 10.1038/s41598-018-27737-y

Li, L., Yu, F., Zheng, L., Wang, R., Yan, W., Wang, Z., et al. (2018b). Natural hydrogels for cartilage regeneration: Modification, preparation and application. J. Orthopaed. Translat. 17, 26-41. doi: 10.1016/j.jot.2018.09.003

$\mathrm{Li}, \mathrm{W}$., Zhou, J., and Xu, Y. (2015). Study of the in vitro cytotoxicity testing of medical devices. Biomed. Rep. 3, 617-620. doi: 10.3892/br.2015.481

Li, Y., Zhou, J., Yang, X., Jiang, Y., and Gui, J. (2016). Intermittent hydrostatic pressure maintains and enhances the chondrogenic differentiation of cartilage progenitor cells cultivated in alginate beads. Dev. Growth Differentiation 58, 180-193. doi: 10.1111/dgd.12261

Lin, H. Y., Tsai, W. C., and Chang, S. H. (2017). Collagen-PVA aligned nanofiber on collagen sponge as bi-layered scaffold for surface cartilage repair. J. Biomater. Sci. 28, 664-678. doi: 10.1080/09205063.2017.1295507

Liu, A., Jennings, L. M., Ingham, E., and Fisher, J. (2015). Tribology studies of the natural knee using an animal model in a new whole joint natural knee simulator. J. Biomechan. 48, 3004-3011. doi: 10.1016/j.jbiomech.2015. 07.043

Liu, F., Kozanek, M., Hosseini, A., Van de Velde, S. K., Gill, T. J., Rubash, H. E., et al. (2010). In vivo tibiofemoral cartilage deformation during the stance phase of gait. J. Biomechan. 43, 658-665. doi: 10.1016/j.jbiomech.2009.10.028

Lo Monaco, M., Merckx, G., Ratajczak, J., Gervois, P., Hilkens, P., Clegg, P., et al. (2018). Stem cells for cartilage repair: preclinical studies and insights in translational animal models and outcome measures. Stem Cells Int. 2018:9079538. doi: 10.1155/2018/9079538

Lo, G. H., Hunter, D. J., Nevitt, M., Lynch, J., McAlindon, T. E., and OAI Investigators Group (2009). Strong association of MRI meniscal derangement and bone marrow lesions in knee osteoarthritis: data from the osteoarthritis initiative. Osteoarthritis and cartilage, 17, osteoarthritis knees are characterized by sclerotic bone that is less well mineralized. Arthritis Res. Ther. 11:R11. doi: $10.1016 /$ j.joca.2008.11.014

Loening, A. M., James, I. E., Levenston, M. E., Badger, A. M., Frank, E. H., Kurz, B., et al. (2000). Injurious mechanical compression of bovine articular cartilage induces chondrocyte apoptosis. Arch. Biochem. Biophys. 381 205-212. doi: 10.1006/abbi.2000.1988

Madi, K., Staines, K. A., Bay, B. K., Javaheri, B., Geng, H., Bodey, A. J., et al. (2020). In situ characterization of nanoscale strains in loaded whole joints via synchrotron X-ray tomography. Nat. Biomed. Eng. 4, 343-354. doi: 10.1038/s41551-019-0477-1

Mak, A. F. (1986). The apparent viscoelastic behavior of articular cartilage-the contributions from the intrinsic matrix viscoelasticity and interstitial fluid flows. J. Biomechan. Eng. 108, 123-130. doi: 10.1115/1.3138591

Mantha, S., Pillai, S., Khayambashi, P., Upadhyay, A., Zhang, Y., Tao, O., et al. (2019). Smart hydrogels in tissue engineering and regenerative medicine. Materials 12:3323. doi: 10.3390/ma12203323

Marchiori, G., Berni, M., Boi, M., and Filardo, G. (2019). Cartilage mechanical tests: evolution of current standards for cartilage repair and tissue engineering. A literature review. Clin. Biomechan. 68, 58-72. doi: 10.1016/j.clinbiomech.2019.05.019

Mata, M., Milian, L., Oliver, M., Zurriaga, J., Sancho-Tello, M., de Llano, J., et al. (2017). In vivo articular cartilage regeneration using human dental pulp stem cells cultured in an alginate scaffold: a preliminary study. Stem Cells Int. 2017:8309256. doi: 10.1155/2017/8309256

Mathis, D. T., Kaelin, R., Rasch, H., Arnold, M. P., and Hirschmann, M. T. (2018). Good clinical results but moderate osseointegration and defect filling of a cell-free multi-layered nano-composite scaffold for treatment of osteochondral lesions of the knee. Knee Surgery Sports Traumatol Arthroscopy. 26, 1273-1280. doi: 10.1007/s00167-017-4638-z

Mcllwraith, C. W., Fortier, L. A., Frisbie, D. D., and Nixon, A. J. (2011). Equine models of articular cartilage repair. Cartilage 2, 317-326. doi: $10.1177 / 1947603511406531$

McLeod, M. A., Wilusz, R. E., and Guilak, F. (2013). Depth-dependent anisotropy of the micromechanical properties of the extracellular and pericellular matrices of articular cartilage evaluated via atomic force microscopy. J. Biomech. 46, 586-592. doi: 10.1016/j.jbiomech.2012.09.003

Medvedeva, E. V., Grebenik, E. A., Gornostaeva, S. N., Telpuhov, V. I., Lychagin, A. V., Timashev, P. S., et al. (2018). Repair of damaged articular 
cartilage: current approaches and future directions. Int. J. Mol. Sci. 19:2366. doi: 10.3390/ijms19082366

Meehan, J., Danielsen, B. H., Kim, S. H., Jamali, A. A., and White, R. H. (2014). Younger age is associated with a higher risk of early periprosthetic joint infection and aseptic mechanical failure after total knee arthroplasty. J. Bone Joint Surg. 96, 529-535. doi: 10.2106/JBJS.M.00545

Mente, P. L., and Lewis, J. L. (1994). Elastic modulus of calcified cartilage is an order of magnitude less than that of subchondral bone. J. Orthopaed. Res. 12, 637-647. doi: 10.1002/jor.1100120506

Merlin Rajesh Lal, L. P., Suraishkumar, G. K., and Nair, P. D. (2017). Chitosan-agarose scaffolds supports chondrogenesis of Human Wharton's Jelly mesenchymal stem cells. J. Biomed. Mater. Res. Part A 105, 1845-1855. doi: 10.1002/jbm.a.36054

Minas, T., Von Keudell, A., Bryant, T., and Gomoll, A. H., (2014). The John Insall Award: a minimum 10-year outcome study of autologous chondrocyte implantation. Clin. Orthopaed. Relat. Res. 472, 41-51. doi: 10.1007/s11999-013-3146-9

Mistry, H., Connock, M., Pink, J., Shyangdan, D., Clar, C., Royle, P., et al. (2017). Autologous chondrocyte implantation in the knee: systematic review and economic evaluation. Health Technol. Assess. 21, 1-294. doi: 10.3310/hta21060

Miyanishi, K., Trindade, M. C., Lindsey, D. P., Beaupr,é, G. S., Carter, D. R., Goodman, S. B., et al. (2006a). Effects of hydrostatic pressure and transforming growth factor-beta 3 on adult human mesenchymal stem cell chondrogenesis in vitro. Tissue Eng. 12, 1419-1428. doi: 10.1089/ten.2006.12.1419

Miyanishi, K., Trindade, M. C., Lindsey, D. P., Beaupr,é, G. S., Carter, D. R., Goodman, S. B., et al. (2006b). Dose- and time-dependent effects of cyclic hydrostatic pressure on transforming growth factor-beta3-induced chondrogenesis by adult human mesenchymal stem cells in vitro. Tissue Eng. 12, 2253-2262. doi: 10.1089/ten.2006.12.2253

Montagne, K., Onuma, Y., Ito, Y., Aiki, Y., Furukawa, K. S., and Ushida, T. (2017). High hydrostatic pressure induces pro-osteoarthritic changes in cartilage precursor cells: a transcriptome analysis. PLOS ONE 12:e0183226. doi: 10.1371/journal.pone. 0183226

Moore, A. C., and Burris, D. L. (2015). Tribological and material properties for cartilage of and throughout the bovine stifle: support for the altered joint kinematics hypothesis of osteoarthritis. Osteoarthritis Cartilage 23, 161-169. doi: $10.1016 /$ j.joca.2014.09.021

Morrison, J. B. (1970). The mechanics of the knee joint in relation to normal walking. J. Biomech. 3, 51-61. doi: 10.1016/0021-9290(70)90050-3

Mow, V. C., Kuei, S. C., Lai, W. M., and Armstrong, C. G. (1980). Biphasic creep and stress relaxation of articular cartilage in compression? Theory and experiments. J. Biomech. Eng. 102, 73-84. doi: 10.1115/1.3138202

Muzzarelli, R. A., El Mehtedi, M., Bottegoni, C., Aquili, A., and Gigante, A. (2015). Genipin-crosslinked chitosan gels and scaffolds for tissue engineering and regeneration of cartilage and bone. Marine Drugs 13, 7314-7338. doi: $10.3390 / \mathrm{md} 13127068$

Nakagawa, K., Teramura, T., Takehara, T., Onodera, Y., Hamanishi, C., Akagi, M., et al. (2012). Cyclic compression-induced p38 activation and subsequent MMP13 expression requires Rho/ROCK activity in bovine cartilage explants. Inflammation Res. 61, 1093-1100. doi: 10.1007/s00011-012-0500-4

Narayanan, G., Vernekar, V. N., Kuyinu, E. L., and Laurencin, C. T. (2016). Poly (lactic acid)-based biomaterials for orthopaedic regenerative engineering. $A d v$. Drug Delivery Rev. 107, 247-276. doi: 10.1016/j.addr.2016.04.015

Nebelung, S., Post, M., Raith, S., Fischer, H., Knobe, M., Braun, B., et al. (2017). Functional in situ assessment of human articular cartilage using MRI: a whole-knee joint loading device. Biomech. Model Mechanobiol. 16, 1971-1986. doi: 10.1007/s10237-017-0932-4

Nguyen, Q. T., Hwang, Y., Chen, A. C., Varghese, S., and Sah, R. L. (2012). Cartilage-like mechanical properties of poly (ethylene glycol)-diacrylate hydrogels. Biomaterials 33, 6682-6690. doi: 10.1016/j.biomaterials.2012.06.005

Niemeyer, P., Laute, V., Zinser, W., John, T., Becher, C., Diehl, P., et al. (2020). Safety and efficacy of matrix-associated autologous chondrocyte implantation with spheroid technology is independent of spheroid dose after 4 years. Knee Surgery Sports Traumatol. Arthroscop. 28, 1130-1143. doi: 10.1007/s00167-019-05786-8

Nukavarapu, S. P., and Dorcemus, D. L. (2013). Osteochondral tissue engineering: current strategies and challenges. Biotechnology. Adv. 31, 706-721. doi: 10.1016/j.biotechadv.2012.11.004
Ogawa, R., Mizuno, S., Murphy, G. F., and Orgill, D. P. (2009). The effect of hydrostatic pressure on three-dimensional chondroinduction of human adipose-derived stem cells. Tissue Eng. Part A 15, 2937-2945. doi: $10.1089 /$ ten.tea.2008.0672

Ogawa, R., Orgill, D. P., Murphy, G. F., and Mizuno, S. (2015). Hydrostatic pressure-driven three-dimensional cartilage induction using human adiposederived stem cells and collagen gels. Tissue Eng. Part A, 21, 257-266. doi: 10.1089/ten.tea.2013.0525

Olivares-Navarrete, R., Lee, E. M., Smith, K., Hyzy, S. L., Doroudi, M., Williams, J. K., et al. (2017). Substrate stiffness controls osteoblastic and chondrocytic differentiation of mesenchymal stem cells without exogenous stimuli. PLoS ONE 12:e0170312. doi: 10.1371/journal.pone.0170312

Oliveira, A. S., Seidi, O., Ribeiro, N., Colaço, R., and Serro, A. P. (2019), Tribomechanical comparison between PVA hydrogels obtained using different processing conditions and human cartilage. Materials 12:3413. doi: $10.3390 / \mathrm{ma1} 2203413$

Olubamiji, A. D., Izadifar, Z., Si, J. L., Cooper, D. M., Eames, B. F., and Chen, D. X. (2016). Modulating mechanical behaviour of 3D-printed cartilage-mimetic PCL scaffolds: influence of molecular weight and pore geometry. Biofabrication 8:025020. doi: 10.1088/1758-5090/8/2/025020

Oyen, M. L. (2014). Mechanical characterisation of hydrogel materials. Int. Mater. Rev. 59, 44-59. doi: 10.1179/1743280413Y.0000000022

Panadero, J. A., Sencadas, V., Silva, S. C., Ribeiro, C., Correia, V., Gama, F. M., et al. (2016). Mechanical fatigue performance of PCL-chondroprogenitor constructs after cell culture under bioreactor mechanical stimulus. J. Biomed. Mater. Res. Appl. Biomater. 104, 330-338. doi: 10.1002/jbm.b.33386

Park, J. S., Chu, J. S., Tsou, A. D., Diop, R., Tang, Z., Wang, A., et al. (2011). The effect of matrix stiffness on the differentiation of mesenchymal stem cells in response to TGF- $\beta$. Biomaterials 32, 3921-3930. doi: 10.1016/j.biomaterials.2011.02.019

Párraga Quiroga, J. M., Wilson, W., Ito, K., and van Donkelaar, C. C. (2017). The effect of loading rate on the development of early damage in articular cartilage. Biomechan. Model. Mechanobiol. 16, 263-273. doi: 10.1007/s10237-016-0815-0

Patel, J. M., Wise, B. C., Bonnevie, E. D., and Mauck, R. L. (2019). A systematic review and guide to mechanical testing for articular cartilage tissue engineering. Tissue Eng. 25, 593-608. doi: 10.1089/ten.tec.2019.0116

Peng, Z., Yang, X., Liu, C., Dong, Z., Wang, F., Wang, X., et al. (2019). Structural and mechanical properties of silk from different instars of Bombyx mori. Biomacromolecules 20, 1203-1216. doi: 10.1021/acs.biomac.8b01576

Petri, M., Broese, M., Simon, A., Liodakis, E., Ettinger, M., Guenther, D., et al. (2013). CaReS (MACT) versus microfracture in treating symptomatic patellofemoral cartilage defects: a retrospective matched-pair analysis. J. Orthopaedic Sci. 18, 38-44. doi: 10.1007/s00776-012-0305-x

Pfeifer, C. G., Karl, A., Kerschbaum, M., Berner, A., Lang, S., Schupfner, R., et al. (2019). TGF- $\beta$ signalling is suppressed under pro-hypertrophic conditions in MSC chondrogenesis due to TGF- $\beta$ receptor downregulation. Int. J. Stem Cells 12, 139-150. doi: $10.15283 /$ ijsc 18088

Prein, C., Warmbold, N., Farkas, Z., Schieker, M., Aszodi, A., and Clausen-Schaumann, H. (2016). Structural and mechanical properties of the proliferative zone of the developing murine growth plate cartilage assessed by atomic force microscopy. Matrix Biol. 50, 1-15. doi: 10.1016/j.matbio.2015.10.001

Qi, Y., Wang, H., Wei, K., Yang, Y., Zheng, R. Y., Kim, I. S., et al. (2017). A review of structure construction of silk fibroin biomaterials from single structures to multi-level structures. Int. J. Mol. Sci. 18:237. doi: 10.3390/ijms18030237

Redondo, M. L., Naveen, N. B., Liu, J. N., Tauro, T. M., Southworth, T. M., and Cole, B. J. (2018). Preservation of knee articular cartilage. Sports Med. Arthrosc. Rev. 26:e23-e30. doi: 10.1097/JSA.0000000000000226

Reppel, L., Schiavi, J., Charif, N., Leger, L., Yu, H., Pinzano, A., et al. (2015). Chondrogenic induction of mesenchymal stromal/stem cells from Wharton's jelly embedded in alginate hydrogel and without added growth factor: an alternative stem cell source for cartilage tissue engineering. Stem Cell Res. Ther. 6:260. doi: 10.1186/s13287-015-0263-2

Richter, D. L., Schenck, R. C. Jr, Wascher, D. C., and Treme, G. (2016). Knee articular cartilage repair and restoration techniques: a review of the literature. Sports Health 8, 153-160. doi: 10.1177/1941738115611350

Rieder, B., Weihs, A. M., Weidinger, A., Szwarc, D., Nürnberger, S., Redl, H., et al. (2018). Hydrostatic pressure-generated reactive oxygen species 
induce osteoarthritic conditions in cartilage pellet cultures. Sci. Rep. 8:17010. doi: 10.1038/s41598-018-34718-8

Robinson, D. L., Kersh, M. E., Walsh, N. C., Ackland, D. C., de Steiger, R. N., and Pandy, M. G. (2016). Mechanical properties of normal and osteoarthritic human articular cartilage. J. Mech. Behav. Biomed. Mater. 61, 96-109. doi: 10.1016/j.jmbbm.2016.01.015

Roffi, A., Kon, E., Perdisa, F., Fini, M., Di Martino, A., Parrilli, A., et al. (2019). A composite chitosan-reinforced scaffold fails to provide osteochondral regeneration. Int. J. Mol. Sci. 20:2227. doi: 10.3390/ijms20092227

Rowland, R., Colello, M., and Wyland, D. J. (2019). Osteochondral autograft transfer procedure: arthroscopic technique and technical pearls. Arthroscopy Techniques 8, e713-e719. doi: 10.1016/j.eats.2019.03.006

Ruvinov, E., Tavor Re'em, T., Witte, F., and Cohen, S. (2018). Articular cartilage regeneration using acellular bioactive affinity-binding alginate hydrogel: a 6month study in a mini-pig model of osteochondral defects. J. Orthopaed. Translat. 16, 40-52. doi: 10.1016/j.jot.2018.08.003

Sadeghi, A. H., Shin, S. R., Deddens, J. C., Fratta, G., Mandla, S., Yazdi, I. K., et al. (2017). Engineered 3D cardiac fibrotic tissue to study fibrotic remodeling. $A d v$. Healthcare Mater. 6:1601434. doi: 10.1002/adhm.201601434

Sadeghi, H., Shepherd, D. E. T., and Espino, D. M. (2015). Effect of the variation of loading frequency on surface failure of bovine articular cartilage. Osteoarthrit. Cartilage 23. 2252-2258. doi: 10.1016/j.joca.2015.06.002

Saha, A., Rolfe, R., Carroll, S., Kelly, D. J., and Murphy, P. (2017). Chondrogenesis of embryonic limb bud cells in micromass culture progresses rapidly to hypertrophy and is modulated by hydrostatic pressure. Cell Tissue Res. 368, 47-59. doi: 10.1007/s00441-016-2512-9

Saidova, A. A., and Vorobjev, I. A. (2020). Lineage commitment, signaling pathways, and the cytoskeleton systems in mesenchymal stem cells. Tissue Eng. Part B Rev. 26, 13-25. doi: 10.1089/ten.teb.2019.0250

Samavedi, S., Poindexter, L., Dyke, M., and Goldstein, A. (2013). "Synthetic Biomaterials for Regenerative Medicine Applications." in the Regenerative Medicine Applications in Organ Transplantation, 81-99. doi: 10.1016/B978-0-12-398523-1.00007-0

Sanchez-Adams, J., Leddy, H. A., McNulty, A. L., O'Conor, C. J., and Guilak, F. (2014). The mechanobiology of articular cartilage: bearing the burden of osteoarthritis. Curr. Rheumatol. Rep. 16:451. doi: 10.1007/s11926-014-0451-6

Sánchez-Téllez, D. A., Téllez-Jurado, L., and Rodríguez-Lorenzo, L. M. (2017). Hydrogels for cartilage regeneration, from polysaccharides to hybrids. Polymers 9:671. doi: 10.3390/polym9120671

Saris, D., Price, A., Widuchowski, W., Bertrand-Marchand, M., Caron, J., Drogset, J. O., et al. (2014). Matrix-applied characterized autologous cultured chondrocytes versus microfracture: two-year follow-up of a prospective randomized trial. Am. J. Sports Med. 42, 1384-1394. doi: $10.1177 / 0363546514528093$

Sawatjui, N., Limpaiboon, T., Schrobback, K., and Klein, T. (2018). Biomimetic scaffolds and dynamic compression enhance the properties of chondrocyteand MSC-based tissue-engineered cartilage. J. Tissue Eng. Regenerat. Med. 12, 1220-1229. doi: 10.1002/term.2653

Scalzone, A., Ferreira, A. M., Tonda-Turo, C., Ciardelli, G., Dalgarno, K., and Gentile, P. (2019). The interplay between chondrocyte spheroids and mesenchymal stem cells boosts cartilage regeneration within a 3D naturalbased hydrogel. Sci. Rep, 9:14630. doi: 10.1038/s41598-019-51070-7

Schinagl, R. M., Gurskis, D., Chen, A. C., and Sah, R. L. (1997). Depth-dependent confined compression modulus of full-thickness bovine articular cartilage. J. Orthopaedic Res. 15, 499-506. doi: 10.1002/jor.1100150404

Scholten, P. M., Ng, K. W., Joh, K., Serino, L. P., Warren, R. F., Torzilli, P. A., et al. (2011). A semi-degradable composite scaffold for articular cartilage defects. J. Biomed. Mater. Res. 97A, 8-15. doi: 10.1002/jbm.a.33005

Shapiro, F., Koide, S., and Glimcher, M. J. (1993). Cell origin and differentiation in the repair of full-thickness defects of articular cartilage. J. Bone Joint Surg. Am. 75, 532-553. doi: 10.2106/00004623-199304000-00009

Sheehy, E. J., Mesallati, T., Vinardell, T., and Kelly, D. J. (2015). Engineering cartilage or endochondral bone: a comparison of different naturally derived hydrogels. Acta Biomaterial. 13, 245-253. doi: 10.1016/j.actbio.2014. 11.031

Sophia Fox, A. J., Bedi, A., and Rodeo, S. A. (2009). The basic science of articular cartilage: structure, composition, and function. Sports Health 1, 461-468. doi: $10.1177 / 1941738109350438$
Stambough, J. B., Clohisy, J. C., Barrack, R. L., Nunley, R. M., and Keeney, J. A. (2014). Increased risk of failure following revision total knee replacement in patients aged 55 years and younger. Bone Joint J. 96-B, 1657-1662. doi: 10.1302/0301-620X.96B12.34486

Stavenschi, E., Corrigan, M. A., Johnson, G. P., Riffault, M., and Hoey, D. A. (2018). Physiological cyclic hydrostatic pressure induces osteogenic lineage commitment of human bone marrow stem cells: a systematic study. Stem Cell Res. Ther. 9:276. doi: 10.1186/s13287-018-1025-8

Stavenschi, E., and Hoey, D. A. (2019). Pressure-induced mesenchymal stem cell osteogenesis is dependent on intermediate filament remodeling. FASEB J. 33, 4178-4187. doi: 10.1096/fj.201801474RR

Steinmetz, N. J., Aisenbrey, E. A., Westbrook, K. K., Qi, H. J., and Bryant, S. J. (2015). Mechanical loading regulates human MSC differentiation in a multilayer hydrogel for osteochondral tissue engineering. Acta Biomaterial. 21, 142-153. doi: 10.1016/j.actbio.2015.04.015

Sun, A. X., Lin, H., Fritch, M. R., Shen, H., Alexander, P. G., DeHart, M., et al. (2017). Chondrogenesis of human bone marrow mesenchymal stem cells in 3-dimensional, photocrosslinked hydrogel constructs: effect of cell seeding density and material stiffness. Acta Biomaterial. 58, 302-311. doi: 10.1016/j.actbio.2017.06.016

Sun, H. B., Zhao, L., Tanaka, S., and Yokota, H. (2012). Moderate joint loading reduces degenerative actions of matrix metalloproteinases in the articular cartilage of mouse ulnae. Connective Tissue Res. 53, 180-186. doi: 10.3109/03008207.2011.628765

Teixeira, M. A., Amorim, M., and Felgueiras, H. P. (2019). Poly(Vinyl Alcohol)based nanofibrous electrospun scaffolds for tissue engineering applications. Polymers 12:7. doi: 10.3390/polym 12010007

Theodoropoulos, J. S., De Croos, J. N. A., Park, S. S., Pilliar, R., and Kandel, R. A., (2011). Integration of tissue-engineered cartilage with host cartilage: an in vitro model. Clin. Orthop. Relat. Res. 469:2785. doi: 10.1007/s11999-011-1856-4

Thomas, L., Vg, R., and Nair, P. R.(2017). Effect of stiffness of chitosanhyaluronic acid dialdehyde hydrogels on the viability and growth of encapsulated chondrocytes. Int. J. Biol. Macromolecules 104(Pt B), 1925-1935. doi: 10.1016/j.ijbiomac.2017.05.116

Thorpe, S. D., Buckley, C. T., Vinardell, T., O’Brien, F. J., Campbell, V. A., and Kelly, D. J. (2008). Dynamic compression can inhibit chondrogenesis of mesenchymal stem cells. Biochem. Biophys. Res. 377, 458-462. doi: 10.1016/j.bbrc.2008.09.154

Thorpe, S. D., Buckley, C. T., Vinardell, T., O'Brien, F. J., Campbell, V. A., and Kelly, D. J. (2010). The response of bone marrow-derived mesenchymal stem cells to dynamic compression following TGF-beta3 induced chondrogenic differentiation. Annals Biomed. Eng. 38, 2896-2909. doi: 10.1007/s10439-010-0059-6

Torres, L., Dunlop, D. D., Peterfy, C., Guermazi, A., Prasad, P., Hayes, K. W., et al. (2006). The relationship between specific tissue lesions and pain severity in persons with knee osteoarthritis. Osteoarthritis Cartilage 14, 1033-1040. doi: 10.1016/j.joca.2006.03.015

Tozzi, G., de Mori, A., Oliveira, A., and Roldo, M. (2016). Composite hydrogels for bone regeneration. Materials 9:267. doi: 10.3390/ma9040267

Tozzi, G., Peña Fernández, M., Davis, S., Karali, A., Kao, A. P., and Blunn, G. (2020). Full-Field Strain Uncertainties and Residuals at the cartilage-bone interface in unstained tissues using propagation-based phase-contrast XCT and digital volume correlation. Materials 13:2579. doi: 10.3390/ma13112579

Trombino, S., Servidio, C., Curcio, F., and Cassano, R. (2019). Strategies for hyaluronic acid-based hydrogel design in drug delivery. Pharmaceutics 11:407. doi: 10.3390/pharmaceutics11080407

Tseng, T. H., Jiang, C. C., Lan, H. H., Chen, C. N., and Chiang, H. (2020). The five year outcome of a clinical feasibility study using a biphasic construct with minced autologous cartilage to repair osteochondral defects in the knee. Int. Orthopaedics 44, 1745-1754. doi: 10.1007/s00264-020-04569-y

Usami, Y., Gunawardena, A. T., Iwamoto, M., and Enomoto-Iwamoto, M. (2016). Wnt signaling in cartilage development and diseases: lessons from animal studies. Lab. Investigat. 96, 186-196. doi: 10.1038/labinvest.2015.142

U. S. Food and Drug Administration (2011). Guidance for Industry: Preparation of IDEs and INDs for Products Intended to Repair Or Replace Knee Cartilage. Available online at: https://www.fda.gov/media/82562/download.

Van Den Bulcke, A. I., Bogdanov, B., De Rooze, N., Schacht, E. H., Cornelissen, M., and Berghmans, H. (2000). Structural and rheological properties of 
methacrylamide modified gelatin hydrogels. Biomacromolecules 1, 31-38. doi: 10.1021/bm990017d

Vanwanseele, B., Eckstein, F., Knecht, H., Stüssi, E., and Spaepen, A. (2002). Knee cartilage of spinal cord-injured patients displays progressive thinning in the absence of normal joint loading and movement. Arthritis Rheum. 46, 2073-2078. doi: 10.1002/art.10462

Varun, T. K., Senani, S., Jayapal, N., Chikkerur, J., Roy, S., Tekulapally, V. B., et al. (2017). Extraction of chitosan and its oligomers from shrimp shell waste, their characterization and antimicrobial effect. Vet. World 10, 170-175. doi: 10.14202/vetworld.2017.170-175

Vikingsson, L., Gómez-Tejedor, J. A., Gallego Ferrer, G., and Gómez Ribelles, J. L. (2015). An experimental fatigue study of a porous scaffold for the regeneration of articular cartilage. J. Biomechan. 48, 1310-1317. doi: 10.1016/j.jbiomech.2015.02.013

Vilela, C. A., da Silva Morais, A., Pina, S., Oliveira, J. M., Correlo, V. M., Reis, R. L., et al. (2018). Clinical trials and management of osteochondral lesions. Adv. Exp. Med. Biol. 1058, 391-413. doi: 10.1007/978-3-31976711-6_18

Vinardell, T., Rolfe, R. A., Buckley, C. T., Meyer, E. G., Ahearne, M., Murphy, P., et al. (2012). Hydrostatic pressure acts to stabilise a chondrogenic phenotype in porcine joint tissue derived stem cells. Eur. Cells Mater. 23, 121-134. doi: 10.22203/eCM.v023a09

Visser, J., Melchels, F. P., Jeon, J. E., van Bussel, E. M., Kimpton, L. S., Byrne, H. M., et al. (2015). Reinforcement of hydrogels using threedimensionally printed microfibres. Nat. Commun. 6:6933. doi: 10.1038/ncomm s7933

Waldman, S. D., Couto, D. C., Grynpas, M. D., Pilliar, R. M., and Kandel, R. A. (2006). A single application of cyclic loading can accelerate matrix deposition and enhance the properties of tissue-engineered cartilage. Osteoarthritis Cartilage 14, 323-330. doi: 10.1016/j.joca.2005. 10.007

Walter, C., Leichtle, U., Lorenz, A., Mittag, F., Wülker, N., Müller, O., et al. (2013). Dissipated energy as a method to characterize the cartilage damage in large animal joints: an in vitro testing model. Med. Eng. Phys. 35, 1251-1255. doi: 10.1016/j.medengphy.2013. 01.002

Wang, T., Lai, J. H., and Yang, F. (2016). Effects of hydrogel stiffness and extracellular compositions on modulating cartilage regeneration by mixed populations of stem cells and chondrocytes in vivo. Tissue Eng. Part A, 22, 1348-1356. doi: 10.1089/ten.tea.2016.0306

Whitney, G. A., Jayaraman, K., Dennis, J. E., and Mansour, J. M. (2017). Scaffoldfree cartilage subjected to frictional shear stress demonstrates damage by cracking and surface peeling. J. Tissue Eng. Regenerat. Med. 11, 412-424. doi: $10.1002 /$ term.1925

Williams, R. J., and Gamradt, S. C. (2008). Articular cartilage repair using a resorbable matrix scaffold. Instructional Course Lectures 57, 563-571.

Wong, B. L., and Sah, R. L. (2010). Mechanical asymmetry during articulation of tibial and femoral cartilages: local and overall compressive and shear deformation and properties. J. Biomechanics 43, 1689-1695. doi: 10.1016/j.jbiomech.2010.02.035

Woodard, L. N., and Grunlan, M. A. (2018). Hydrolytic degradation and erosion of polyester biomaterials. ACS Macro Lett. 7, 976-982. doi: 10.1021 /acsmacrolett.8b00424

Wu, J. Z., Herzog, W., and Hasler, E. M. (2002). Inadequate placement of osteochondral plugs may induce abnormal stress-strain distributions in articular cartilage -finite element simulations. Med. Eng. Phys. 24, 85-97. doi: 10.1016/S1350-4533(01)00122-9
Xia, H., Liang, C., Luo, P., Huang, J., He, J., Wang, Z., et al. (2018). Pericellular collagen I coating for enhanced homing and chondrogenic differentiation of mesenchymal stem cells in direct intra-articular injection. Stem Cell Res. Therapy 9:174. doi: 10.1186/s13287-018-0916-Z

Xia, T., Liu, W., and Yang, L. (2017). A review of gradient stiffness hydrogels used in tissue engineering and regenerative medicine. J. Biomed. Mater. Res. Part A 105, 1799-1812. doi: 10.1002/jbm.a.36034

Xu, J., Wang, W., Ludeman, M., Cheng, K., Hayami, T., Lotz, J. C., et al. (2008). Chondrogenic differentiation of human mesenchymal stem cells in three-dimensional alginate gels. Tissue Eng. Part A. 14, 667-680. doi: 10.1089/tea.2007.0272

Yamagata, K., Nakayamada, S., and Tanaka, Y. (2018). Use of mesenchymal stem cells seeded on the scaffold in articular cartilage repair. Inflammation Regenerat. 38:4. doi: 10.1186/s41232-018-0061-1

Yang, J., Zhang, Y. S., Yue, K., and Khademhosseini, A. (2017). Cell-laden hydrogels for osteochondral and cartilage tissue engineering. Acta Biomaterial. 57, 1-25. doi: 10.1016/j.actbio.2017.01.036

Yao, Y., Zeng, L., and Huang, Y. (2016). The enhancement of chondrogenesis of ATDC5 cells in RGD-immobilized microcavitary alginate hydrogels. J. Biomater. Appl. 31, 92-101. doi: 10.1177/0885328216640397

Zak, L., Albrecht, C., Wondrasch, B., Widhalm, H., Vekszler, G., Trattnig, S., et al. (2014). Results 2 years after matrix-associated autologous chondrocyte transplantation using the novocart 3D Scaffold: an analysis of clinical and radiological data. Am. J. Sports Med. 42, 1618-1627. doi: $10.1177 / 0363546514532337$

Zhang, T., Wen, F., Wu, Y., Goh, G. S., Ge, Z., Tan, L. P., et al. (2015). Cross-talk between TGF-beta/SMAD and integrin signaling pathways in regulating hypertrophy of mesenchymal stem cell chondrogenesis under deferral dynamic compression. Biomaterials. (2015) 38:72-85. doi: 10.1016/j.biomaterials.2014.10.010

Zheng, L., Liu, S., Cheng, X., Qin, Z., Lu, Z., Zhang, K., et al. (2019). Intensified stiffness and photodynamic provocation in a collagenbased composite hydrogel drive chondrogenesis. Adv. Sci. 6:1900099. doi: $10.1002 /$ advs.201900099

Zhu, J. (2010). Bioactive modification of poly(ethylene glycol) hydrogels for tissue engineering. Biomaterials 31, 4639-4656. doi: 10.1016/j.biomaterials.2010.02.044

Zhu, Y., Wu, H., Sun, S., Zhou, T., Wu, J., and Wan, Y. (2014). Designed composites for mimicking compressive mechanical properties of articular cartilage matrix. J. Mech. Behav. Biomed. Mater. 36, 32-46. doi: 10.1016/j.jmbbm.2014.04.003

Zikria, B., Hafezi-Nejad, N., Patten, I., Johnson, A., Haj-Mirzaian, A., Wilckens, J. H., et al. (2019). Image-guided chondrocyte harvesting for autologous chondrocyte implantation: initial feasibility study with human cadaver and pilot clinical experience. JB JS Open Access 4:e0039. doi: 10.2106/JBJS.OA.18.00039

Conflict of Interest: The authors declare that the research was conducted in the absence of any commercial or financial relationships that could be construed as a potential conflict of interest.

Copyright $\odot 2021$ Davis, Roldo, Blunn, Tozzi and Roncada. This is an open-access article distributed under the terms of the Creative Commons Attribution License (CC $B Y)$. The use, distribution or reproduction in other forums is permitted, provided the original author(s) and the copyright owner(s) are credited and that the original publication in this journal is cited, in accordance with accepted academic practice. No use, distribution or reproduction is permitted which does not comply with these terms. 